\title{
Intraoperative fluorescence imaging with aminolevulinic acid detects grossly occult breast cancer: a phase II randomized controlled trial
}

Kathryn Ottolino-Perry , Anam Shahid', Stephanie DeLuca', Viktor Son ${ }^{1,2}$, Mayleen Sukhram,2, Fannong Meng ${ }^{1,2}$, Zhihui ( Amy) Liu, Sara Rapic', Nayana Thalanki Anantha', Shirley C. Wang1', Emilie Chamma', Christopher Gibson', Philip J. Medeiros', Safa Majeed ${ }^{1}$, Ashley Chu', Olivia Wignall', Alessandra Pizzolato', Cheryl F. Rosen ${ }^{4}$, Liis Lindvere Teene ${ }^{1}$, Danielle Starr-Dunham ${ }^{1}$, Iris Kulbatski ${ }^{1}$, Tony Panzarella ${ }^{3}$, Susan J. Done ${ }^{1,2,5}$, Alexandra M. Easson ${ }^{1,6}$, Wey L. Leong ${ }^{1,6}$ and Ralph S. DaCosta ${ }^{1,7,8^{*}}$

\begin{abstract}
Background: Re-excision due to positive margins following breast-conserving surgery (BCS) negatively affects patient outcomes and healthcare costs. The inability to visualize margin involvement is a significant challenge in BCS. 5-Aminolevulinic acid hydrochloride (5-ALA HCl), a non-fluorescent oral prodrug, causes intracellular accumulation of fluorescent porphyrins in cancer cells. This single-center Phase II randomized controlled trial evaluated the safety, feasibility, and diagnostic accuracy of a prototype handheld fluorescence imaging device plus 5-ALA for intraoperative visualization of invasive breast carcinomas during BCS.

Methods: Fifty-four patients were enrolled and randomized to receive no 5-ALA or oral 5-ALA HCl (15 or $30 \mathrm{mg} /$ $\mathrm{kg}$ ). Forty-five patients ( $n=15 /$ group) were included in the analysis. Fluorescence imaging of the excised surgical specimen was performed, and biopsies were collected from within and outside the clinically demarcated tumor border of the gross specimen for blinded histopathology.

Results: In the absence of 5-ALA, tissue autofluorescence imaging lacked tumor-specific fluorescent contrast. Both 5-ALA doses caused bright red tumor fluorescence, with improved visualization of tumor contrasted against normal tissue autofluorescence. In the $15 \mathrm{mg} / \mathrm{kg}$ 5-ALA group, the positive predictive value (PPV) for detecting breast cancer inside and outside the grossly demarcated tumor border was $100.0 \%$ and $55.6 \%$, respectively. In the $30 \mathrm{mg} /$ kg 5-ALA group, the PPV was $100.0 \%$ and $50.0 \%$ inside and outside the demarcated tumor border, respectively. No adverse events were observed, and clinical feasibility of this imaging device-5-ALA combination approach was confirmed.
\end{abstract}

\footnotetext{
* Correspondence: rdacosta@uhnresearch.ca

'Princess Margaret Cancer Centre, University Health Network, Ontario Cancer Institute, 101 College Street, Toronto M5G 1L7, Ontario, Canada

${ }^{7}$ Department of Medical Biophysics, Faculty of Medicine, University of

Toronto, 101 College Street, Toronto M5G 1L7, Ontario, Canada

Full list of author information is available at the end of the article
}

(C) The Author(s). 2021 Open Access This article is licensed under a Creative Commons Attribution 4.0 International License, which permits use, sharing, adaptation, distribution and reproduction in any medium or format, as long as you give appropriate credit to the original author(s) and the source, provide a link to the Creative Commons licence, and indicate if changes were made. The images or other third party material in this article are included in the article's Creative Commons licence, unless indicated otherwise in a credit line to the material. If material is not included in the article's Creative Commons licence and your intended use is not permitted by statutory regulation or exceeds the permitted use, you will need to obtain permission directly from the copyright holder. To view a copy of this licence, visit http://creativecommons.org/licenses/by/4.0/ The Creative Commons Public Domain Dedication waiver (http://creativecommons.org/publicdomain/zero/1.0/) applies to the data made available in this article, unless otherwise stated in a credit line to the data. 
Conclusions: This is the first known clinical report of visualization of 5-ALA-induced fluorescence in invasive breast carcinoma using a real-time handheld intraoperative fluorescence imaging device.

Trial registration: Clinicaltrials.gov identifier NCT01837225. Registered 23 April 2013.

Keywords: Breast cancer, Breast-conserving surgery, Fluorescence imaging, Intraoperative imaging, Aminolevulinic acid, Margin assessment, Optical imaging, Handheld intraoperative imaging device

\section{Introduction}

Breast cancer, the most prevalent cancer in women, is often treated by breast-conserving surgery (BCS) $[1,2]$ which aims to completely excise the tumor with clear margins while preserving the maximum amount of healthy tissue. Cancer visualization under standard white light (WL) operating room conditions is difficult due to low cancer-to-normal tissue contrast, resulting in positive margins which are related to greater risk of local recurrence (LR) [3-6], inferior outcomes (complications, stress, poor cosmesis) [7], adjuvant delay [8], increased healthcare costs [9-11], and lower disease-specific survival [12]. Furthermore, incomplete resection requires reoperation in $20-70 \%$ of patients [2, 6, 13-20]. Thus, reducing positive margin rates is a major goal in BCS [21] and is an internationally recognized quality indicator for treatment $[7,22]$.

Currently, BCS best practice uses WL visualization, palpation, specimen radiography, and intraoperative histopathology to guide resection. These techniques are lengthy ( $20 \mathrm{~min})$ [23], limited by inaccurate colocalization of positive margins on the excised tissue to the surgical bed [24] and variably impact outcomes [23]. Adaptation of standard medical imaging technologies for operating room use (MRI [25], ultrasound [25, 26], PET/ CT [25]), and emerging intraoperative tumor detection technologies for BCS, both non-optical and optically enabled, are either at the preclinical stage or are not widely adopted due to practical limitations. Thus, there is a clinical need for an alternative, safe, practical, costsensitive, and real-time intraoperative imaging technology for surgeons and pathologists to visualize occult malignancy in excised specimens and surgical cavities during index BCS.

Fluorescence imaging using an intraoperative instrument plus an exogenous tumor-specific imaging agent may fulfill this need by enhancing tumor tissue contrast and facilitating the detection of grossly occult disease. Intraoperative fluorescence imaging for detection of carcinoma has been demonstrated in clinical trials for several tumor types using visible and near-infrared (NIR) contrast agents [27-30]. However, the instrumentation involves large, costly cart-based systems that are impractical for BCS since they do not fulfill the surgeon's need to interrogate both the surgical specimen and cavity. To address this, we developed a handheld fluorescence imaging device (Portable Real-time Optical Detection Identification and Guide for Intervention, PRODIGI) for real-time intraoperative fluorescence imaging of excised breast specimens and the surgical cavity. PRODIGI is clinically safe and has demonstrated clinical utility in other medical applications [31-33]. The device combines consumer-grade imaging sensor technology with miniature light-emitting diodes (LEDs) and multiband optical filtering to capture high-resolution WL and fluorescence digital images and videos. PRODIGI's multiband optical filter allows for imaging of porphyrins, including protoporphyrin IX (PpIX), which fluoresces red (peak emission at $635 \mathrm{~nm}$ wavelength) $[34,35]$ when excited by violet-blue light $(\sim 400-410 \mathrm{~nm})$. PpIX is a metabolite of the prodrug 5-aminolevulinic acid (5-ALA), an endogenous non-protein amino acid involved in heme biosynthesis in mammalian cells. Unlike contrast agents that are receptor-targeted or enzyme-activated, PpIX is not affected by suboptimal biodistribution and tumor penetration, heterogenous target receptor/enzyme expression [29], and high background fluorescence [29, 36].

Delivered systemically, 5-ALA is taken up by cells throughout the body where it is converted into heme. In aberrant cells, such as cancer cells, defects in heme biosynthesis cause accumulation of PpIX [35, 37-42], enabling real-time visualization. 5-ALA is widely known for its clinical use in photodynamic diagnosis [43-55] and therapy $[34,49,56,57]$ of premalignant and malignant disease. Large clinical trials have demonstrated the safety and clinical utility of 5-ALA-based fluorescence imageguided surgery (FIGS) for malignant glioma [58-61], which led to the approval of oral 5-ALA hydrochloride $(\mathrm{HCl})$ for FIGS of high-grade glioma in approximately 40 countries, including the USA [62]. Other clinical studies support 5-ALA for the visualization of malignant tissue in the bladder [44], gastrointestinal tract [50], oral cavity [51, 52], lung [47, 55], and female genital tract $[49,53,54] .5$-ALA has a well-established safety profile, which is highlighted in the Gleolan Prescribing Information for glioma patients where pyrexia, hypotension, nausea, and vomiting are reported to have occurred in > $1 \%$ of patient's in the week following surgery and chills, photosensitivity reaction, solar dermatitis, hypotension, 
abnormal liver function test, and diarrhea are reported to have occurred in $<1 \%$ of patients in the 6 weeks after surgery [62]. Only one other clinical study (in 2001) explored the utility of 5 -ALA ( $40 \mathrm{mg} / \mathrm{kg}$ bodyweight (BW)) for detecting breast cancers in a non-randomized study of 16 patients, although the results were exploratory and limited to imaging surgical specimens only [48]. Since then, no follow-up studies on the application of 5-ALA in breast cancer imaging have been published.

In this report, we present the results of a single-center non-interventional Phase II randomized controlled trial (RCT) designed to characterize the imaging performance of our handheld imaging device with two doses (15 and $30 \mathrm{mg} / \mathrm{kg} \mathrm{BW}$ ) of 5-ALA $\mathrm{HCl}$ versus no tumor contrast in patients with invasive breast cancer undergoing lumpectomy or mastectomy. Two doses (15 or $30 \mathrm{mg} / \mathrm{kg} \mathrm{BW}$ ) of 5-ALA $\mathrm{HCl}$ were administered to evaluate the minimum dosage for sufficient tumor-to-normal tissue fluorescence contrast obtained using the PRODIGI device. The doses selected are "on either side" of the FDAapproved dose for glioma (20 mg/kg) [62] and are based on previous clinical studies validating safety at $\leq 60 \mathrm{mg} /$ $\mathrm{kg}$ [63-65], tumor enhancement as low as $10 \mathrm{mg} / \mathrm{kg}$ [59, $60,64]$, and improved tumor-to-normal tissue contrast with increased doses [60, 64]. The primary objective was to determine measures of diagnostic accuracy (positive and negative predictive values, sensitivity, specificity, and diagnostic odds ratio) of visualization of breast tumors in surgical specimens using PRODIGI in combination with 5-ALA $\mathrm{HCl}$, with ex vivo biopsy-based histology as the gold standard. The secondary objective was to evaluate the feasibility and safety of the PRODIGI device for intraoperative imaging of the surgical cavity following resection. Finally, we confirm the safety and technical feasibility and discuss the future clinical adoptability of PRODIGI plus 5-ALA $\mathrm{HCl}$ to improve tumor visualization during BCS.

\section{Materials and methods Study design}

The Princess Margaret Cancer Center (PMCC; Toronto, Canada), University Health Network (UHN) Research Ethics Board (REB\#10-0633-CE) and Mount Sinai Hospital (MSH; Toronto, Canada) Research Ethics Board (REB\#13-0155E) approved the clinical protocol for this study (clinicaltrials.gov identifier NCT01837225). All subjects provided written informed consent and were randomized to receive no 5 -ALA, 15 , or $30 \mathrm{mg} / \mathrm{kg} 5$ ALA $\sim 3 \mathrm{~h}$ before surgery ( $2-4 \mathrm{~h}$ prior to anesthesia). A randomization table was generated before study initiation using the List Randomization tool from RANDOM.org and stored in a locked cabinet. The primary objective of this RCT was to determine measures of diagnostic accuracy of PpIX fluorescence for visualizing breast tumors in patients receiving oral 5ALA HCl. Participants underwent standard breast cancer surgery (lumpectomy or mastectomy) by one of two study surgeons (A.M.E., W.L.L.), followed by fluorescence imaging of the cavity and surgical specimen by a researcher, and collection of biopsies from the surgical specimen by the pathologist's assistant (PA) (V.S., M.S., F.M.). The first 5 patients randomized per group underwent ex vivo imaging of the surgical specimen only. Imaging of the surgical cavity and specimen was performed in the remaining 10 patients/group. Neither the surgeon (A.M.E., W.L.L.), researcher, nor PA (V.S., M.S., F.M.) were blinded to allocation.

Imaging was performed en face of the external surface of the intact surgical specimens followed by the serially sliced specimen (1-1.5 cm thickness/slice). Biopsies were collected from two spatially distinct areas of specimen slices: (i) inside the grossly demarcated primary tumor border near the center of the tumor and (ii) outside the grossly demarcated primary tumor border (see Study Workflow, Supplementary Fig. 1). Biopsies were collected from areas of red and non-red fluorescence tissue to determine the accuracy of fluorescence visualization of clinically obvious (inside the tumor border) and clinically occult (outside the tumor border) disease. A pathologist (S.J.D.) blinded to fluorescence imaging results evaluated biopsies for the presence of cancer (including invasive and in situ disease). Surgeons (A.M.E., W.L.L.) and pathologists (S.J.D.) did not modify their conventional margin assessment based on fluorescence imaging results or use fluorescence imaging to guide resection.

\section{Study population}

Patients were screened for eligibility by their breast cancer surgeon (A.M.E., W.L.L.) during their pre-operative clinic visits. The inclusion criteria were as follows: $\geq 18$ years of age, female, diagnosed with invasive breast cancer, primary tumor measuring $\geq 2 \mathrm{~cm}$ in diameter based on diagnostic imaging, consented to standard surgeries for primary invasive breast cancer with/without axillary procedure (axillary dissection or sentinel node biopsy), and consented to banking of core biopsies with UHN tissue bank. The exclusion criteria were as follows: preoperative therapy (chemotherapy, endocrine therapy, radiotherapy), history of photosensitivity, liver disease or recurrent disease, pregnant, tumor diameter $<2 \mathrm{~cm}$ at grossing (as stipulated by the pathology department), unable to consent, or refused tissue banking. Seventy patients were consented to participate in the study, of which 14 were withdrawn prior to randomization and 9 after randomization (Fig. 1) due to the following reasons: tumor diameters measuring $<2 \mathrm{~cm}$ at the time of gross examination, change of treatment plan to include preoperative chemotherapy or surgery at a hospital other 


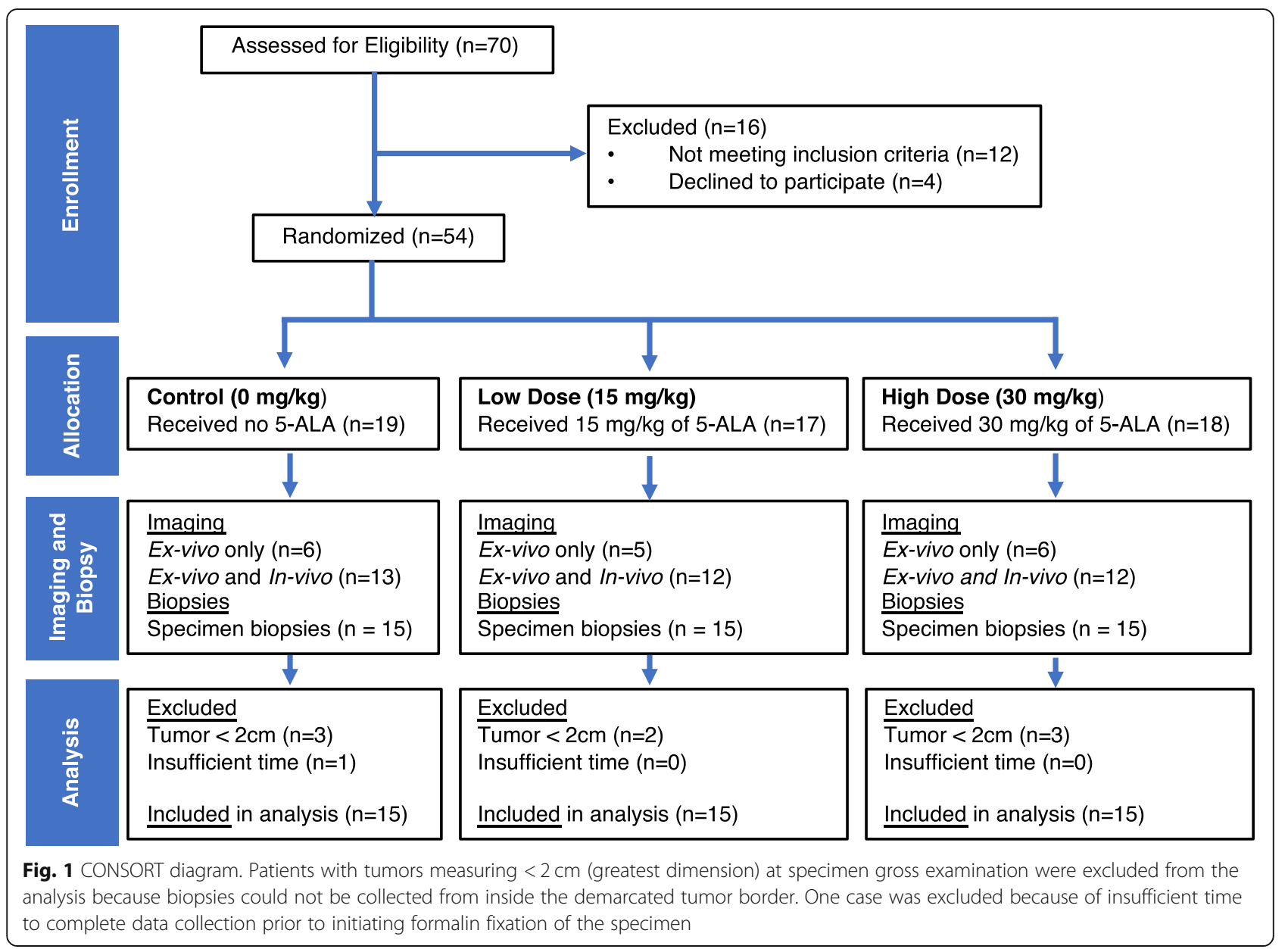

than PMCC or patient choice. Data from withdrawn participants was not included in the patient demographics or data analysis.

\section{5-ALA HCl doses and administration}

5-ALA $\mathrm{HCl}$ (generously provided by photonamic GmbH and Co. KG, Pinneberg, Germany) was dissolved in tap water and administered orally by a study nurse $2-4 \mathrm{~h}$ before surgery in patients randomized to the 15 or $30 \mathrm{mg} / \mathrm{kg}$ BW 5-ALA groups. Precautionary measures were taken to prevent adverse events related to 5-ALA, including monitoring for symptoms related to skin photosensitivity [63-65] and providing homecare instructions to minimize exposure to sunlight and/or bright indoor light for at least $48 \mathrm{~h}$ following 5-ALA ingestion. Patients were provided with SPF 60 sunscreen and instructed how to use it prior to leaving the hospital. Patient records were reviewed for any adverse events reported at the post-surgical follow-up with their surgeon (A.M.E., W.L.L.).

\section{Handheld fluorescence imaging device}

PRODIGI (Supplementary Fig. 2) is a handheld fluorescence imaging device prototype developed by our group for clinical fluorescence imaging applications [60, 61]. PRODIGI emits $405 \mathrm{~nm}$ light with an optical power density of $1.14 \mathrm{~mW} / \mathrm{cm}^{2}$ at a $10-\mathrm{cm}$ imaging distance. Fluorescence imaging was performed with all room lights turned off and intrinsic camera sensor settings (e.g., ISO: Auto; Exposure Value: 0; Macro: Auto) were kept the same across all image acquisition sessions. The device was cleaned with disinfecting wipes between uses. Images were transferred to a designated passwordprotected personal computer after each imaging session for storage and analysis. The device was Canadian Standards Association certified for electrical safety prior to use and exempt from Health Canada Investigational Testing Authorization requirements.

\section{In vivo fluorescence imaging of the surgical cavity}

The technical feasibility, safety, and integration into the clinical workflow of in vivo imaging of the surgical cavity immediately following lumpectomy or mastectomy was 
examined using PRODIGI in $\mathrm{n}=30$ ( $\mathrm{n}=10$ /group) patients. The device and its power supply cable were covered in a disposable sterile plastic drape (Laser Arm Drape, Cardinal Health, 29-59029) using an instrument draping protocol to maintain sterility. Small neodymium magnets permanently embedded in the device were attached to four autoclaved magnets on the exterior of the drape thereby holding the drape flush against the emission filter. The draping protocol complied with the safety requirements of the International Electrotechnical Commission IEC 60601-1 such that heat generated from the LEDs was safely dissipated within the drape during use. Real-time still and video WL and fluorescence imaging of the cavity was performed by a member of the research team with the assistance of the surgeon (A.M.E., W.L.L.), who manipulated the cavity to expose the entire inner surface of the cavity. Overhead room lights and surgical lights were turned off during fluorescence imaging.

\section{Ex vivo specimen preparation, image acquisition, and interpretation}

Following breast cancer surgery, surgical specimens were sent to pathology where WL and fluorescence images were acquired of all anatomical surfaces of the intact specimen. Margins were painted by the PA (V.S., M.S., F.M.) using a standardized margin inking schema (different colors for different margins) following fluorescence imaging of the intact specimen, to avoid ink artefacts. Specimens were serially sliced grossly ("bread-loafed") [66] and the slice containing the largest clinically discernable cross-sectional of tumor was laid open. A digital WL image of the complete slice was transferred to a tablet computer (Galaxy Note, Model GT N8010, Samsung). WL images were indelibly marked by the PA (V.S., M.S., F.M.) using Photoshop (Adobe) to demarcate the clinically identifiable primary tumor border based on visualization and palpation. In cases of nonpalpable cancers or tumors with an ill-defined edge, no primary tumor border was marked. Fluorescence images were collected to ensure each WL image had a spatially colocalized fluorescence image. Specimen imaging was performed with the device held $\sim 10 \mathrm{~cm}$ from the tissue. For scale, a white specimen sticker was used during imaging. Images were date stamped and saved for analysis. Fluorescence images were acquired under low light, consistent across imaging sessions. In some patients, additional WL and fluorescence images of adjacent specimen slices and slices identified by the PA (V.S., M.S., F.M.) as "tumor-free" were collected. WL and fluorescence image acquisition took $<1 \mathrm{~s}$ and $1-2 \mathrm{~s}$, respectively per surface or specimen slice. Specimens were placed in formalin for fixation within $1 \mathrm{~h}$ of surgical excision as per clinical practice.

\section{Tissue biopsy collection and analysis}

Research tissue biopsies were collected by study research staff from ex vivo specimens of all 45 patients $(n=141$ biopsies) for gold standard histological evaluation by the study pathologist (S.J.D.) blinded to the imaging results. A 2- or 4-mm diameter punch biopsy device (Cat \#12460-409 and -399, Thermo Fisher Scientific, New Hampshire, USA) was used. Biopsies were collected from inside and outside the tumor border. Outside the border, fluorescence imaging was used to target biopsy collection in areas with red or no-red PpIX fluorescence. A minimum of 1 biopsy (inside the tumor border, to retain sufficient carcinoma for clinical diagnosis) and a maximum of 4 biopsies (tumor plus additional biopsies, to ensure specimen fixation commenced within an acceptable ischemia time) were collected per specimen (total biopsies $=141)$. Most biopsies $(n=134)$ were fixed in neutral buffered formalin, paraffin-embedded, sectioned $(4 \mu \mathrm{m})$, and H\&E stained. A subset of tumor biopsies (n $=7$ ) were placed in a tissue cassette, immersed in optimal cutting temperature compound, flash frozen in liquid nitrogen, and protected from light using established methods before fluorescence microscopy visualization of the cellular localization of PpIX fluorescence. All H\&E sections were evaluated by the blinded study pathologist (S.J.D.) for invasive and/or in situ cancer. When required, immunohistochemical stains (High Molecular Weight Keratin, Estrogen Receptor, Calponin, Smooth Muscle Myosin, CAM5.2, P63) were performed on serial sections according to standard institutional staining protocols. We used a custom quantitative fluorescence $(\mathrm{qF})$ system [38] to characterize the fluorescence spectra between 500 and $800 \mathrm{~nm}$ emission ( $405 \mathrm{~nm}$ excitation) and measure local tissue PpIX concentration at locations within the primary tumor border before biopsy. Tissue fluorescence spectra were obtained by a fiberoptic probe connected to a bench-top spectrometer, and a validated algorithm was used to calculate absolute PpIX concentrations [38].

\section{Ex vivo tissue fluorescence microscopy}

A subset of biopsies $(n=7)$ from inside the primary tumor border were processed by frozen section for fluorescence microscopy. Frozen biopsies were collected from $\mathrm{n}=4$ low-dose patient specimens and $\mathrm{n}=3$ high-dose patient specimens. Frozen biopsies were cut serially into $8 \mu \mathrm{m}$ frozen tissue sections and placed on glass microscopy slides for confocal fluorescence microscopy before histological staining. Frozen sections were wrapped in tin foil to limit light exposure and stored at $-80^{\circ} \mathrm{C}$ until fluorescence microscopy was performed. Serial sections 
were cut from each biopsy for confocal microscopy, $H \& E$, and additional staining, as required. Slides were imaged with the Nikon A1R resonance scanning confocal fluorescence microscope (Nikon Instruments Inc. Melville, NY, U.S.A.) using $405 \mathrm{~nm}$ excitation, a 525/50$\mathrm{nm}$ emission filter for background tissue autofluorescence (AF) and a 600/50 + 685/70-nm emission filter for PpIX fluorescence. Resonance mode was used to scan frozen tissue sections rapidly (30 or 420 frames/second), to optimize image acquisition settings and minimize photobleaching of PpIX fluorescence. Fluorescence images were acquired using Galvano scanning at $1024 \times$ 1024 pixels.

Immediately following fluorescence microscopy, frozen sections were fixed in formalin and stained with H\&E. Two additional serial sections of the same sample were stained using standard protocols with Masson's trichrome (MT) to identify connective tissues and Oil Red $\mathrm{O}(\mathrm{ORO})$ to identify adipocytes. This enabled spatial correlation between fluorescent tissue features in the frozen section and tissue-specific staining for histology. Nikon NIS Elements C software (Nikon Instruments Inc. Melville, NY, USA) was used to convert fluorescence microscopy images to TIF format and Aperio ImageScope was used to export corresponding images of H\&E, MT, and ORO-stained tissues to JPEG image format. Fluorescence $\mathrm{H} \& \mathrm{E}, \mathrm{MT}$, and ORO-stained tissue section images were examined by the study pathologist (S.J.D.).

\section{Image analysis of stained tissue sections}

Stained biopsy tissue sections from 5-ALA patient specimens were digitalized using the Aperio Scanscope XT whole-slide scanner (Aperio Technologies, Inc., Vista, CA, USA). HALO Image Analysis software v2.0.1145.14 (Indica Labs, Albuquerque, NM, USA) was used to quantify the area and relative amount tissue types (cancer, connective, adipose) within biopsies histologically confirmed to contain cancer cells based on pathologist (S.J.D.)-blinded examination. A blinded researcher used the HALO Classifier Module to train the proprietary machine-learning algorithm to identify and differentiate tissues based on differences in color, texture, and contextual features. Previous work has validated this software for detecting pathology in human paraffinembedded tissue [67]. Up to four different classifiers were defined per tissue section: carcinoma, connective, adipose tissue, and non-tissue area (background). Areas corresponding to each tissue type were manually highlighted to provide training inputs and refined for each section with additional training inputs to improve accuracy. Cancer cells, stromal tissue, and adipocytes were identified with the aid of the Classifier Module and the area $\left(\mathrm{mm}^{2}\right)$ for each tissue type as well as the total biopsy slice area was obtained based on pixel algorithms.
The percentage of cancer tissue (area of cancer pixels/ area of tissue pixels) and connective tissue (area connective tissue pixels/area of tissue pixels) was calculated, as well as the ratio of tumor over connective tissue (area of tumor pixels/area of connective tissue pixels). Aperio ImageScope (Aperio Technologies, Inc., Vista, CA, USA) was used to export images of H\&E-stained sections in JPEG format for publication.

\section{Analyses of clinical fluorescence images}

Fluorescence images of serially sliced specimens were analyzed using Matlab v2018b (The MathWorks, Inc., Massachusetts, USA). Slices annotated with the primary tumor border were included ( $\mathrm{n}=14$, control; $\mathrm{n}=11$, low dose; $\mathrm{n}=12$, high dose). During gross examination, the PA (V.S., M.S., F.M.) identified the primary tumor of 8 specimens as having ill-defined borders and the images were not annotated with the clinically demarcated primary tumor border. These 8 specimens were excluded from this analysis. JPEG images were converted from RGB to XYZ format using an inbuilt Matlab function. Regions of interest corresponding to the primary tumor and normal tissue were defined based on the clinically demarcated primary tumor border. Background areas without tissue or that included the scale bar sticker, and areas outside the primary tumor that had histologically confirmed cancer were excluded. The average $\mathrm{X}, \mathrm{Y}$, and $\mathrm{Z}$ values for all pixels in the primary tumor ROI and normal tissue ROI were calculated, converted into $(x$, $y)^{\text {tumor }}$ and $(x, y)^{\text {normal }}$ coordinates, and plotted on a CIE chromaticity graph. The Euclidean distance between $(x$, $y)^{\text {tumor }}$ and $(x, y)^{\text {normal }}$, which corresponds to a perceived difference in color according to the MacAdams diagram (Supplementary Fig. 3), was calculated per image using an inbuilt Matlab program. The average \pm standard deviation Euclidean distance for images from patients in each group was compared.

\section{Statistical analysis}

Specimen fluorescence images and corresponding research tissue biopsies $(n=93)$ from patients treated with 5-ALA were used to estimate the PPV, NPV, sensitivity, specificity, and diagnostic odds ratio (DOR) of the device plus 5-ALA to differentiate between breast cancer and healthy tissues. The exact method (Pearson-Clopper) was used to calculate the $95 \%$ confidence intervals of the estimated PPV, NPV, sensitivity and specificity, and normal approximation on logarithmic scale was used for the confidence intervals of the DOR. True positives were biopsies from a PpIX red fluorescence area, histologically confirmed as cancer cell positive (invasive and/or in situ), whereas false positives were biopsies from a red fluorescence area, histologically confirmed as cancer cell negative. True negatives were biopsies from a non- 
Table 1 Baseline characteristics and surgical procedures

\begin{tabular}{|c|c|c|c|c|}
\hline & Control $(n=15)$ & Low Dose $(n=15)$ & High Dose $(n=15)$ & Total $(n=45)$ \\
\hline Age (years) (mean, SD) & $55.5(15.3)$ & $57.5(13.2)$ & $53.8(9.9)$ & $55.6(12.8)$ \\
\hline \multicolumn{5}{|l|}{ Surgery Type (N, \%) } \\
\hline Lumpectomy & $10(66.7)$ & $9(60.0)$ & $10(66.7)$ & $29(64.4)$ \\
\hline Mastectomy & $5(33.3)$ & $6(37.5)$ & $5(33.3)$ & $16(35.5)$ \\
\hline \multicolumn{5}{|l|}{ Diagnosis $(\mathrm{N}, \%)$} \\
\hline IDC & $13(86.7)$ & $13(86.7)$ & $11(73.3)$ & $37(82.2)$ \\
\hline ILC & $1(6.7)$ & $2(13.3)$ & $4(26.7)$ & $7(15.6)$ \\
\hline IMC & $1(6.7)$ & $0(0.0)$ & $0(0.0)$ & $1(6.7)$ \\
\hline Primary Tumour Size $(\mathrm{cm})$ (mean, SD) & $3.1(1.2)$ & $2.7(0.9)$ & $3.3(2.2)$ & $3.0(1.5)$ \\
\hline \multicolumn{5}{|l|}{ Grade (N, \%) } \\
\hline 1 & $1(6.7)$ & $1(6.7)$ & $1(6.7)$ & $3(6.7)$ \\
\hline 2 & $4(26.6)$ & $6(40.0)$ & $5(33.3)$ & $15(33.3)$ \\
\hline 3 & $10(66.7)$ & $8(53.3)$ & $9(60.0)$ & $27(60.0)$ \\
\hline \multicolumn{5}{|l|}{ Mitotic Score (N, \%) } \\
\hline 1 & $4(26.7)$ & $5(33.3)$ & $5(33.3)$ & $14(31.1)$ \\
\hline 2 & $3(20.0)$ & $3(20.0)$ & $4(26.7)$ & $10(22.2)$ \\
\hline 3 & $8(53.3)$ & $7(46.7)$ & $6(37.5)$ & $21(46.7)$ \\
\hline \multicolumn{5}{|l|}{ ER Status (N, \%) } \\
\hline Positive & $12(80.0)$ & $12(80.0)$ & $11(73.3)$ & $35(77.8)$ \\
\hline Negative & $3(20.0)$ & $3(20.0)$ & $4(26.7)$ & $10(22.2)$ \\
\hline \multicolumn{5}{|l|}{ PR Status (N, \%) } \\
\hline Positive & $12(80.0)$ & $10(66.7)$ & $10(66.7)$ & $32(71.1)$ \\
\hline Negative & $3(20.0)$ & $5(33.3)$ & $5(33.3)$ & $13(28.9)$ \\
\hline \multicolumn{5}{|l|}{ Her2 Status (N, \%) } \\
\hline Positive & $1(6.7)$ & $4(26.7)$ & $2(13.3)$ & $7(15.6)$ \\
\hline Negative & $14(93.3)$ & $11(73.3)$ & $13(86.7)$ & $38(84.4)$ \\
\hline \multicolumn{5}{|l|}{ DCIS Present (N, \%) } \\
\hline Yes & $12(80.0)$ & $10(66.7)$ & $9(60.0)$ & $31(68.9)$ \\
\hline No & $3(20.0)$ & $5(33.3)$ & $6(37.5)$ & $14(31.1)$ \\
\hline \multicolumn{5}{|l|}{ Margin Status (N, \%) } \\
\hline Positive (Invasive) & $1(6.7)$ & $1(6.7)$ & $4(26.7)$ & $6(13.3)$ \\
\hline Negative (Invasive) & $14(93.3)$ & $14(93.3)$ & $11(73.3)$ & $39(86.7)$ \\
\hline Positive (DCIS) & $1(6.7)$ & $0(0.0)$ & $1(6.7)$ & $2(4.4)$ \\
\hline Negative (DCIS) & $14(93.3)$ & $15(100)$ & $14(93.3)$ & $43(95.6)$ \\
\hline \multicolumn{5}{|l|}{ Revised Margins at Index Surgery $(\mathrm{N}, \%)^{\mathrm{a}}$} \\
\hline Yes & $3(20.0)$ & $3(20.0)$ & $4(26.7)$ & $10(22.2)$ \\
\hline No & $12(80.0)$ & $12(80.0)$ & $11(73.3)$ & $35(77.8)$ \\
\hline \multicolumn{5}{|l|}{ Re-excision (N, \%) } \\
\hline Yes & $2(13.3)$ & $1(6.7)$ & $3(20.0)$ & $6(13.3)$ \\
\hline No & $13(86.7)$ & $14(93.3)$ & $12(80.0)$ & $39(86.7)$ \\
\hline
\end{tabular}

$S D$ standard deviation, IDC invasive ductal carcinoma, ILC invasive lobular carcinoma, IMC invasive mammary carcinoma, ER estrogen receptor, $P R$ progesterone receptor, HER2 Human epidermal growth factor receptor 2, DCIS ductal carcinoma in situ

amargin revision not guided by fluorescence imaging 


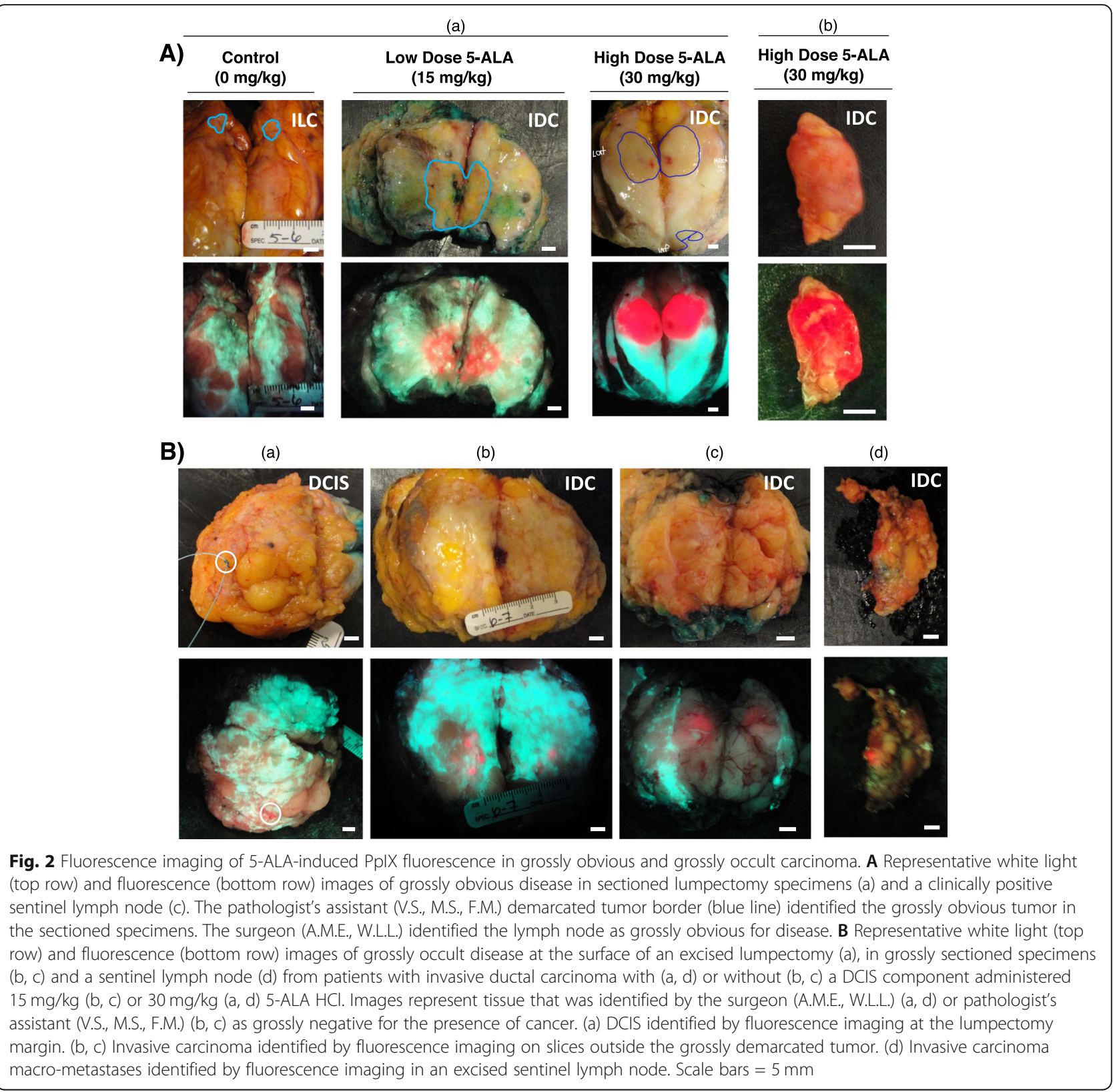

(PpIX) red fluorescence area, histologically confirmed as cancer cell negative, whereas false negatives were biopsies from a non-red fluorescence area, histologically confirmed as cancer cell positive. PPV is defined as the probability of cancer being present in an area of tissue identified as positive for PpIX red fluorescence, and NPV is defined as the probability of cancer being absent in an area of tissue identified as negative for PpIX red fluorescence. DOR is a measure of test performance defined as the ratio of the odds of detecting red PpIX fluorescence if cancer is present relative to the odds of detecting red PpIX fluorescence if cancer is not present. Scatterplots and Mann-Whitney tests were used to compare proportions of cancer and connective tissue, and the ratio of cancer and connective tissue pixels between biopsies from red fluorescence regions. Bar graphs and one-way ANOVA with Tukey's multiple comparisons test were used to compare Euclidean distances between all groups. R v3.4.1 (R Core Team 2017. R: A language and environment for statistical computing. $\mathrm{R}$ Foundation for Statistical Computing, Vienna, Austria) was used to calculate diagnostic measures of accuracy and GraphPad 
Prism v8 (GraphPad Software, Inc. La Jolla, CA) was used to generate graphs and perform Mann-Whitney and ANOVA tests.

\section{Results}

\section{Subject demographics}

Forty-five females (29-83 years old) undergoing lumpectomy $(n=29)$ or mastectomy $(n=16)$ for primary ductal $(n=37)$, lobular $(n=7)$, or mixed $(n=1)$ invasive carcinoma at the Princess Margaret Cancer Center (PMCC, Toronto, Ontario, Canada) between August 2013-August 2018 were included in the analysis (Table 1). Patients were randomized 1:1:1 to receive no 5-ALA (control), $15 \mathrm{mg} / \mathrm{kg}$ (low dose) or 30 $\mathrm{mg} / \mathrm{kg}$ (high dose) BW orally administered 5-ALA 2$4 \mathrm{~h}$ before surgery. Ten patients $(22.2 \%)$ had margins revised at the surgeons' (A.M.E., W.L.L.) discretion during index surgery. Seven (15.6\%) patients had at least one involved margin on the index surgical pathology report, of which $6(13.3 \%)$ were positive for invasive carcinoma and $2(4.44 \%)$ were positive for ductal carcinoma in situ (DCIS). Six of 45 patients (13.3\%) underwent a second operation to achieve negative margins.

In patients receiving 5-ALA, oral administration occurred between 2 and $4 \mathrm{~h}$ before anesthesia with an average time to imaging \pm SD of $248.3 \pm 55.8 \mathrm{~min} v \mathrm{~s}$ $246.1 \pm 37.3 \mathrm{~min}(\mathrm{p}=0.90, \mathrm{t}$-test $)$ for the low- and high-dose 5-ALA groups, respectively.

\section{5-ALA-induced fluorescence in clinically obvious and clinically occult disease}

Bright red PpIX fluorescence was detected inside the demarcated tumor border in grossly sectioned specimens only from patients administered either 5-ALA dose (Fig. 2). PpIX fluorescence was observed in both invasive ductal carcinoma (IDC; with or without DCIS) and invasive lobular carcinoma (ILC). In the absence of 5-ALA, tumor AF was indistinguishable from background normal adipose and connective tissue AF.

Strong PpIX fluorescence was detected in grossly obvious disease (Fig. 2A), which was visibly appreciable and/or palpable both in grossly sectioned surgical specimens (Fig. 2A(a)) and clinically positive tumor-draining lymph nodes (Fig. 2A(b)). The boundary between the PpIX fluorescence primary tumor and surrounding normal tissue of the grossly sectioned specimen was well-defined and aligned closely with that of the pathologist's assistant (PA) (V.S., M.S., F.M.) demarcated tumor border (Fig. 2A(a)). 5ALA-induced PpIX fluorescence was also detected in grossly occult disease, which was not otherwise obvious under intraoperative standard of care (Fig. 2B). Grossly occult disease, including IDC and DCIS, was detected by fluorescence imaging on the margin of the intact specimen (Fig. 2B(a)), in sectioned surgical specimens (Fig. $2 \mathrm{~B}(\mathrm{~b}-\mathrm{c})$ ) and in tumor-draining lymph nodes (Fig. 2B(d)).

Table 2 Performance of fluorescence imaging device to detect carcinoma in patients administered 5-ALA stratified by biopsy location. Measures of diagnostic accuracy were calculated separately for the areas inside and outside the demarcated tumor border. Areas of fluorescence images classified as negative or positive for PplX red fluorescence (-Red FL/+Red FL) were biopsied and fluorescence imaging results were compared to gold-standard histological evaluation of biopsy H\&E tissue sections performed by a blinded pathologist (S.J.D.)

\begin{tabular}{|c|c|c|c|c|c|c|c|c|}
\hline & \multicolumn{4}{|c|}{ Low Dose (15 mg/kg) } & \multicolumn{4}{|c|}{ High Dose $(30 \mathrm{mg} / \mathrm{kg})$} \\
\hline & \multicolumn{2}{|c|}{ Inside the tumor border } & \multicolumn{2}{|c|}{ Outside the tumor border } & \multicolumn{2}{|c|}{ Inside the tumor border } & \multicolumn{2}{|c|}{ Outside the tumor border } \\
\hline & -Cancer & +Cancer & -Cancer & +Cancer & -Cancer & +Cancer & -Cancer & +Cancer \\
\hline -Red FL & 1 & 6 & 21 & 1 & 0 & 5 & 20 & 2 \\
\hline+ Red FL & 0 & 8 & 4 & 5 & 0 & 10 & 5 & 5 \\
\hline $\begin{array}{l}\text { PPV } \\
\%(95 \% \mathrm{Cl})\end{array}$ & \multicolumn{2}{|l|}{$\begin{array}{l}100.0 \% \\
(63.1-100.0)\end{array}$} & \multicolumn{2}{|l|}{$\begin{array}{l}55.6 \% \\
(21.2-86.3)\end{array}$} & \multicolumn{2}{|l|}{$\begin{array}{l}100.0 \% \\
(73.5-100.0)\end{array}$} & \multicolumn{2}{|l|}{$\begin{array}{l}50.0 \% \\
(18.7-81.3)\end{array}$} \\
\hline $\begin{array}{l}\text { NPV } \\
\%(95 \% \mathrm{Cl})\end{array}$ & \multicolumn{2}{|l|}{ N/A } & \multicolumn{2}{|l|}{$\begin{array}{l}95.5 \% \\
(77.2-99.9)\end{array}$} & \multicolumn{2}{|l|}{ N/A } & \multicolumn{2}{|l|}{$\begin{array}{l}90.9 \% \\
(70.8-98.9)\end{array}$} \\
\hline $\begin{array}{l}\text { Sensitivity } \\
\%(95 \% \mathrm{Cl})\end{array}$ & \multicolumn{2}{|l|}{$\begin{array}{l}57.1 \% \\
(28.9-82.3)\end{array}$} & \multicolumn{2}{|l|}{$\begin{array}{l}83.3 \% \\
(35.9-99.6)\end{array}$} & \multicolumn{2}{|l|}{$\begin{array}{l}66.7 \% \\
(38.4-88.2)\end{array}$} & \multicolumn{2}{|l|}{$\begin{array}{l}71.4 \% \\
(29.0-96.3)\end{array}$} \\
\hline $\begin{array}{l}\text { Specificity } \\
\%(95 \% \text { Cl) }\end{array}$ & \multicolumn{2}{|l|}{$\begin{array}{l}100.0 \%^{\mathrm{a}} \\
(2.5-100.0)\end{array}$} & \multicolumn{2}{|l|}{$\begin{array}{l}84.0 \% \\
(63.9-95.5)\end{array}$} & \multicolumn{2}{|l|}{$N / A^{b}$} & \multicolumn{2}{|l|}{$\begin{array}{l}80.0 \% \\
(59.3-93.2)\end{array}$} \\
\hline DOR $(95 \% C l)$ & \multicolumn{2}{|l|}{ N/A } & \multicolumn{2}{|l|}{$\begin{array}{l}26.3 \\
(2.38-288.94)\end{array}$} & \multicolumn{2}{|l|}{ N/A } & \multicolumn{2}{|l|}{$\begin{array}{l}10 \\
(1.5-67.6)\end{array}$} \\
\hline
\end{tabular}

FL fluorescence, $P P V$ positive predictive value, NPV negative predictive value, Cl confidence interval, DOR diagnostic odds ratio, N/A not applicable a a single tumor negative biopsy was collected inside the demarcated tumor border

${ }^{b}$ no tumor negative biopsies collected inside the tumor border 


\section{Diagnostic accuracy of fluorescence imaging with 5-ALA $\mathrm{HCl}$}

Diagnostic measures of accuracy were calculated to evaluate the ability of 5-ALA-induced PpIX red fluorescence to discriminate breast carcinoma using the PRODIGI device. Blinded pathologist (S.J.D.) analysis of hematoxylin and eosin (H\&E)-stained research biopsies served as the gold standard for comparison with fluorescence imaging results. Control tumors (no 5-ALA) appeared as green and pink/brown fluorescence and lacked perceptible fluorescence contrast to differentiate tumors from surrounding healthy tissue (Fig. 2A(a)). As a result, all biopsies collected from control patients $(n=47)$ were classified as negative for PpIX red fluorescence (except a single biopsy, Supplementary Fig. 4). Diagnostic measures of accuracy to detect PpIX red fluorescence tumors are therefore not presented for the control group. Data for the low-dose ( $\mathrm{n}=46$ biopsies) and high-dose ( $\mathrm{n}$ $=48$ biopsies) 5-ALA groups are presented in Table 2 . Measures were calculated separately for the areas inside and outside the grossly demarcated tumor border, accounting for the anticipated difference in cancer prevalence in these areas. The positive predictive value (PPV) was $100.0 \%$ for both the 15 and $30 \mathrm{mg} / \mathrm{kg}$ groups inside the tumor border. Outside the tumor border, the PPV was $55.6 \%$ and $50.0 \%$ for the low- and high-dose groups, respectively. The NPV inside the tumor border is not reported since the prevalence of normal healthy tissue inside the tumor border is expected to be extremely low and therefore the denominator of NPV is expected to be near zero regardless of the results of the fluorescence imaging. However, outside the demarcated tumor border, the NPV was $95.5 \%$ and $90.9 \%$ for the low- and high-dose groups, respectively.

The specificity outside the tumor border was $84.0 \%$ and $80.0 \%$ in the low- and high-dose groups, respectively. The DOR was 26.3 and 10 for the 15 and $30 \mathrm{mg} /$ $\mathrm{kg}$ groups, respectively. The measures of diagnostic accuracy for all biopsies, irrespective of collection location, are presented in Table 3. Overall, sensitivity and specificity to detect cancer was $65.0 \%$ and $84.6 \%$, respectively in the low dose group and $68.2 \%$ and $80.0 \%$, respectively in the high-dose group. The PPV was $76.5 \%$ (low dose) and $75.0 \%$ (high dose) and the NPV was $75.9 \%$ (low dose) and $74.1 \%$ (high dose). No significant difference in the measures of diagnostic accuracy was observed between the low- and high-dose groups (Supplementary Table 1).

Accurate discrimination of small tumor foci was demonstrated by microscopic examination of H\&Estained biopsies collected from a small focus $(\sim 2 \mathrm{~mm}$ diameter) of red fluorescence and nearby non-red fluorescence tissue (Fig. 3A). Fluorescence imaging detected a $0.71-\mathrm{mm}^{2}$ IDC focus (Fig. 3B) within surrounding normal breast tissue (Fig. 3C), otherwise occult to the pathologist (S.J.D.). In another specimen, DCIS $2.6 \mathrm{~mm}$ below the imaged tissue surface was visualized as a small area of red fluorescence (Fig. 3D, E). These data demonstrate the sub-millimeter fluorescence image resolution of our device, the cancer cell-selective nature of 5-ALA, and its ability to detect sub-surface disease.

Confocal fluorescence microscopy of frozen tumor tissue sections from representative patients was used to

Table 3 Performance of fluorescence imaging device to detect carcinoma in patients administered 5-ALA. Overall measures of diagnostic accuracy were calculated irrespective of the biopsy location (analysis combined biopsies collected inside and outside the tumor border). Areas of fluorescence images classified as negative or positive for PpIX red fluorescence (-Red FL/+Red FL) were biopsied and fluorescence imaging results were compared to gold-standard histological evaluation of biopsy H\&E tissue sections performed by a blinded pathologist (S.J.D.)

\begin{tabular}{|c|c|c|c|c|}
\hline & \multicolumn{2}{|c|}{ Low Dose $(15 \mathrm{mg} / \mathrm{kg})$} & \multicolumn{2}{|c|}{ High Dose (30 mg/kg) } \\
\hline & -Cancer & +Cancer & -Cancer & +Cancer \\
\hline -Red FL & 22 & 7 & 20 & 7 \\
\hline+ Red FL & 4 & 13 & 5 & 15 \\
\hline $\begin{array}{l}\text { PPV } \\
\%(95 \% \mathrm{Cl})\end{array}$ & $\begin{array}{l}76.5 \% \\
(50.1-93.2)\end{array}$ & & $\begin{array}{l}75.0 \% \\
(50.9-91.3)\end{array}$ & \\
\hline $\begin{array}{l}\text { NPV } \\
\%(95 \% \mathrm{Cl})\end{array}$ & $\begin{array}{l}75.9 \% \\
(56.5-89.7)\end{array}$ & & $\begin{array}{l}74.1 \% \\
(53.7-88.9)\end{array}$ & \\
\hline $\begin{array}{l}\text { Sensitivity } \\
\%(95 \% \mathrm{Cl})\end{array}$ & $\begin{array}{l}65.0 \% \\
(40.8-84.6)\end{array}$ & & $\begin{array}{l}68.2 \% \\
(45.1-86.1)\end{array}$ & \\
\hline $\begin{array}{l}\text { Specificity } \\
\%(95 \% \text { Cl) }\end{array}$ & $\begin{array}{l}84.6 \% \\
(65.1-95.6)\end{array}$ & & $\begin{array}{l}80.0 \% \\
(59.3-93.2)\end{array}$ & \\
\hline DOR $(95 \% C l)$ & $\begin{array}{l}13.6 \\
(3.0-62.0)\end{array}$ & & $\begin{array}{l}8.6 \\
(2.3-32.4)\end{array}$ & \\
\hline
\end{tabular}

FL fluorescence, $P P V$ positive predictive value, NPV negative predictive value, $C l$ confidence interval, DOR diagnostic odds ratio, N/A not applicable 


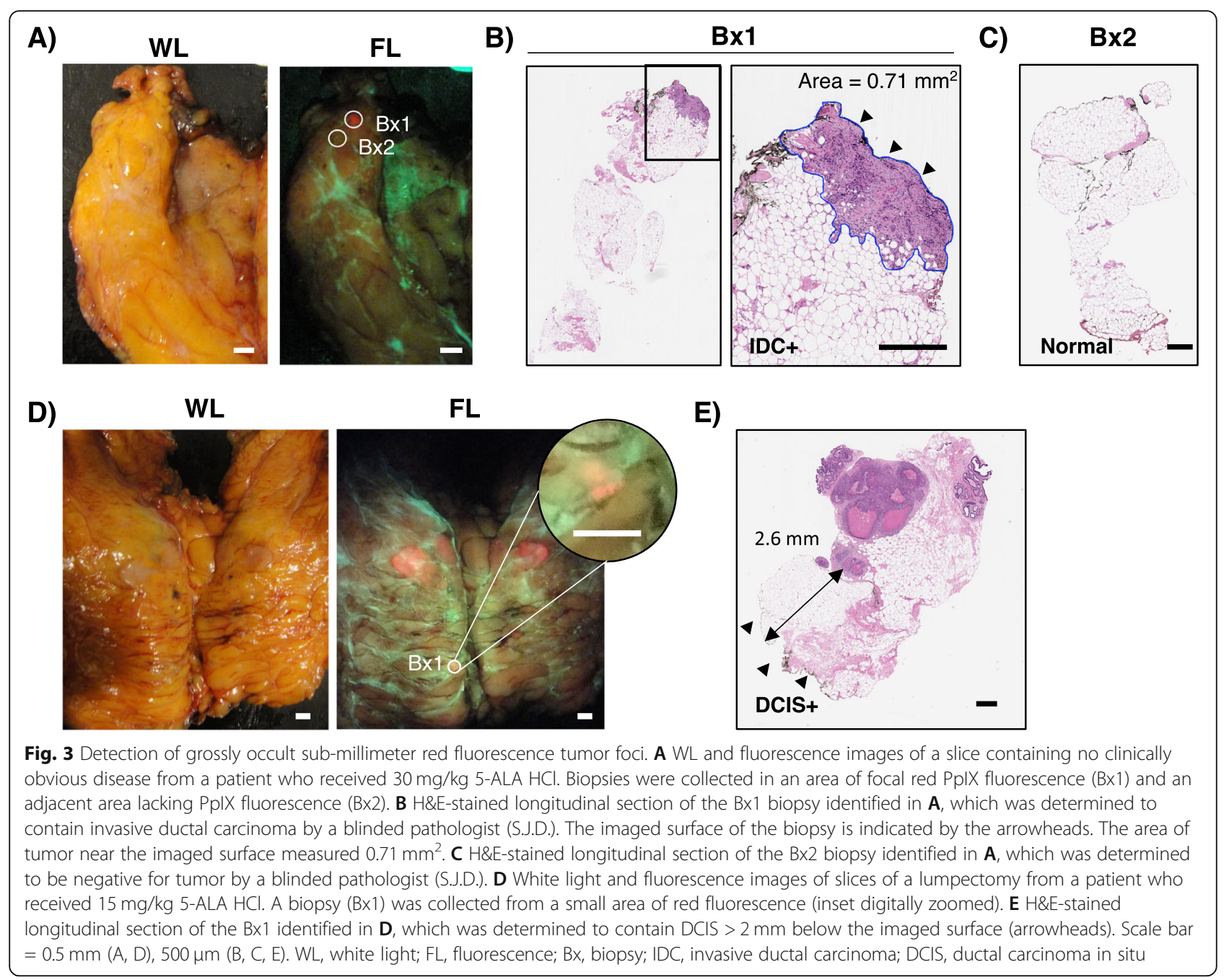

confirm the cancer-specific localization of PpIX and characterize healthy tissue AF. Fluorescence microscopy showed bright PpIX fluorescence in the cytoplasm of cancer cells identified in corresponding H\&E-stained tissue sections (Fig. 4A). No significant red PpIX fluorescence was observed in the cancer stroma, which exhibited bright green AF (Fig. 4A) due to dense connective tissues, such as collagen and elastin, visible in Masson's trichrome-stained section (Fig. 4B) [68]. Adipose tissue, which was identified using Oil Red Ostained sections, was visible in both the green and red channels, demonstrating broad green-to-red AF albeit with a qualitatively subdued intensity compared with the green AF of connective tissues or the red PpIX fluorescence. The boundary between cancer foci containing PpIX fluorescence and connective tissue green AF was distinct at the cellular level (Fig. 4), indicating the specificity of PpIX accumulation in cancer cells compared with healthy surrounding tissues.

\section{Characterization of normal and cancerous breast tissue fluorescence}

To characterize fluorescence features of cancer and normal breast tissues, focal areas inside and outside the demarcated tumor border were visually appraised before biopsy and categorized by a research team member as red, green, or dull pink/brown fluorescence during biopsy (Fig. $5 \mathrm{~A}(\mathrm{a}), \mathrm{B}(\mathrm{a}), \mathrm{C}(\mathrm{a})$ ). H\&E-stained sections were evaluated for carcinoma and other normal breast tissues (Fig. 5A(b), B(b),C(b)). In patients receiving 5-ALA, biopsies from outside the tumor border were obtained from areas of red PpIX fluorescence, if present, while the remaining biopsies were from areas identified as green or pale pink/brown fluorescence. In control and both 5-ALA dose groups, areas of bright green fluorescence on gross imaging corresponded to connective tissues (Fig. 5A-C), while pale pink/brown areas were predominately adipose tissue (Fig. 5A, B). Quantitative fluorescence point spectroscopy performed at biopsy 
A)
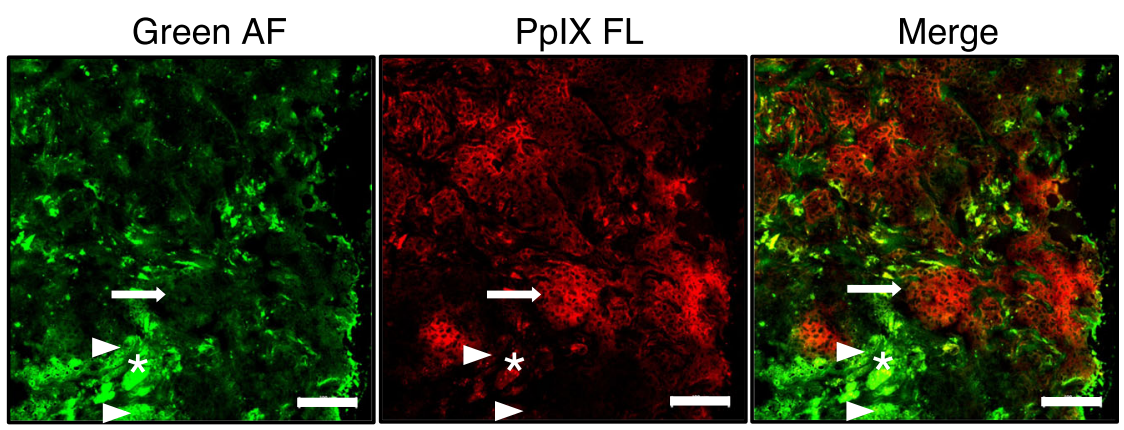

B)

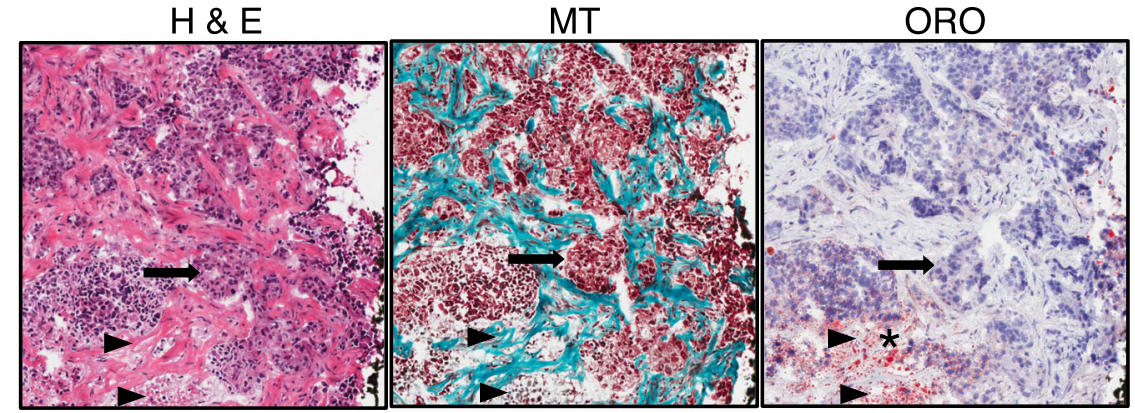

Fig. 4 Cancer cell-specific localization of ALA-induced PpIX fluorescence. Representative $\mathbf{A}$ fluorescence microscopy and $\mathbf{B}$ corresponding histological images (bottom panel) from a biopsy collected inside the demarcated primary tumor boundary of a patient who received $30 \mathrm{mg} / \mathrm{kg}$ 5-ALA. The biopsy appeared red fluorescent with PRODIGI imaging. A Fluorescence microscopy was performed on cryosections cut from tumor core biopsies followed by B H\&E, Masson's Trichrome (MT), and Oil Red O (ORO) staining. Arrowheads depict green AF that was consistently observed in fibrous collagen tissue and in locations of necrosis, as confirmed with H\&E and MT staining. Adipose tissue, identified by ORO staining, demonstrated both green and red AF (asterisk). PpIX fluorescence microscopic imaging confirmed cancer cell localization of PpIX (arrow), which was not observed during green AF imaging. Scale bar $=100 \mu \mathrm{m}$

locations within the demarcated tumor border confirmed PpIX (peak emission $635 \mathrm{~nm}$ ) in red fluorescence tumors of patients that received 5-ALA (Fig. $5 \mathrm{~B}(\mathrm{c})$ and $\mathrm{C}(\mathrm{c})$ ) but not in controls (Fig. $5 \mathrm{~A}(\mathrm{c})$ ). Among both 5ALA groups, histological assessment of $\mathrm{H} \& \mathrm{E}$ tissue sections of biopsies from red fluorescence tumors showed that while fluorescence imaging of the gross specimen often appeared homogeneously bright red in the demarcated primary tumor [due to increased PpIX in cancer cells (Fig. 5C(a), Bx1)], in fact, microscopically, these corresponding tissue regions contained a mixture of cancer and healthy tissue cells (Fig. 5C(b), Bx1). Taken together with our fluorescence microscopy data (Fig. 4), which demonstrated specific accumulation of PpIX in cancer cells and not in interspersed normal tissue, these data demonstrate that visualization based on PpIX red fluorescence is feasible in areas with a mixture of tissue types (malignant, connective and adipose). Additionally, fluorescence imaging revealed the multifocal and spatially heterogeneous nature of invasive breast cancers (Fig. 5C(a), slices 5-6).

To determine the effect of different 5-ALA doses on cancer fluorescence contrast compared with normal tissues, fluorescence images were analyzed in the CIE xyY (chromaticity-luminance) color space, which is more sensitive to differences in fluorescence images than RGB intensity-based analysis [69]. For a given image, the average pixel color ( $x, y$ coordinates) in two regions of interest (ROI) was calculated and the Eucliden distance between these points was measured (Fig. 5D). The average $( \pm$ SD) Euclidean distance for the low-dose $(0.09 \pm$ $0.04)$ and high-dose $(0.10 \pm 0.09) 5$-ALA groups was significantly greater than the control $(0.03 \pm 0.2, \mathrm{p}<0.05$, one-way ANOVA with Tukey's multiple comparison test), confirming the lack of visually perceptible cancer fluorescence contrast in the control group and the improved fluorescence contrast of PpIX red fluorescence cancers relative to healthy background tissue in the 5ALA groups.

\section{Effect of tissue composition on detection of PpIX fluorescence}

The average percentage of the total biopsy area classified as cancer or connective tissue in histologically confirmed cancer cell-positive biopsies was compared between biopsies collected from red fluorescence (true positive) or green fluorescence (false negative) regions (Supplementary Fig. 5). Given that the 5-ALA dose did not significantly affect the classification of biopsies (comparable number of TP and FN were observed between both 5- 

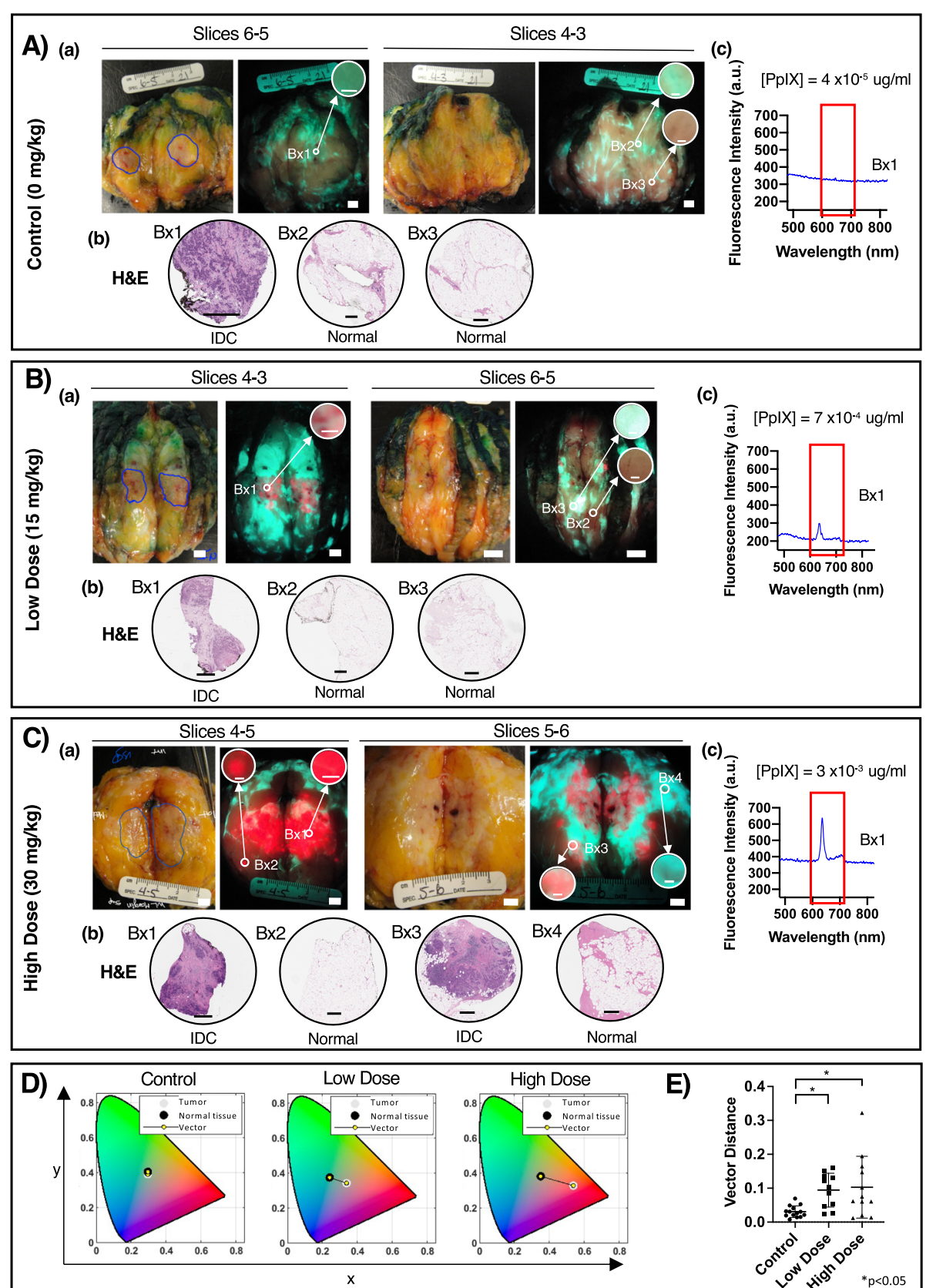

E)

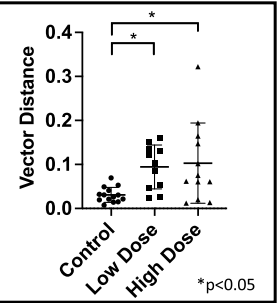

Fig. 5 Ex vivo breast specimen fluorescence in patients with and without 5-ALA. Representative white light and fluorescence images with corresponding biopsy-based H\&E and fluorescence spectra from patients with invasive ductal carcinoma receiving A no 5-ALA, B 15 mg/kg 5ALA, or C 30 mg/kg 5-ALA. (a) Biopsies were collected in areas inside (Bx1) the PA demarcated tumor (blue line) and outside the demarcated tumor (B×2-4) on an adjacent slice of the specimen. Circular insets are digitally magnified images of the biopsy areas demonstrating the fluorescence color. (b) H\&E-stained longitudinal biopsy sections were examined by a blinded pathologist (S.J.D.) for the presence of cancer. (c) Point spectroscopy was performed at the Bx1 location and smoothed fluorescence spectra in the region of PplX emission (red box, $635 \mathrm{~nm}$ peak) are presented. D Representative chromaticity diagrams (CIE xyY displaying the average pixel color inside the demarcated tumor border and outside to normal tissue contrast from fluorescence images of specimens from patients described in parts $\mathbf{A}-\mathbf{C}$ of this figure. $\mathbf{E}$ Bar graph depicting the average vector distance between the average pixel color of the primary tumor and surrounding normal tissue. ${ }^{*} p<0.05$, one-way ANOVA with multiple comparisons. Scale bar $=5 \mathrm{~mm}$ (a, white light and fluorescence images), $100 \mu \mathrm{m}$ (a, inset), $500 \mu \mathrm{m}$ (b, H\&E sections). BX, biopsy; IDC, invasive ductal carcinoma 
ALA dose groups), the data from both dose groups was pooled. While the average percent cancer was higher in biopsies collected from red versus green fluorescence regions, this was not statistically significant (Supplementary Fig. 5A, $24.43 \%$ vs $14.82 \%, p=0.12$ ). Conversely, the average percent connective tissue was significantly lower in biopsies collected from PpIX red versus green fluorescence regions (Supplementary Fig. 5B, 56.04\% vs $73.18 \%, \mathrm{p}=0.007)$. PRODIGI simultaneously detects green and red fluorescence to produce a composite color image; therefore, the relative amount of both connective and cancer tissue is hypothesized to affect the resultant fluorescence color in that region of tissue. The carcinoma-to-connective tissue ratio (area of a biopsy tissue section classified as cancer divided by the area classified as connective tissue) demonstrates that histologically confirmed cancer cell-positive biopsies collected from red fluorescence regions had a significantly higher carcinoma-to-connective tissue ratio compared to those classified as green fluorescence (Supplementary Fig. 5C, 0.49 vs $0.20, \mathrm{p}=0.02$ ).

\section{Safety and feasibility of intraoperative imaging}

No adverse drug reactions or device-related adverse events were observed during the trial. One patient, who reported a sunburn after post-operative discharge, did not adhere to the sun protection instructions. Intraoperative imaging of the surgical cavity was performed in 30 study participants $(n=10 /$ group$)$ to demonstrate technical feasibility, safety, and integration of PRODIGI into the BCS clinical workflow (Supplementary Fig. 6). We noted that the fixed placement of LEDs did not adequately illuminate the entire cavity surface homogeneously. To overcome this, we scanned the surface in a sweeping manner with the device and collected videos of the fluorescence. Cavity imaging integrated into the standard operating room workflow without significant disruption. Approximately 1-2 min was required to perform a complete scan with real-time video display of all anatomical margins of the surgical cavity. The device was quickly and easily draped prior to entering the sterile field and was thermally stable during operation and comfortable for the operator. Furthermore, the device was used to image surgical specimens without workflow disruption in the pathology setting.

\section{Discussion}

We present preliminary evidence of effectiveness from a Phase II RCT demonstrating the first clinical use of 5ALA plus PRODIGI, a prototype fluorescence imaging device, for real-time visualization of breast cancers. The primary objective of this study was to determine estimates of diagnostic accuracy including PPV, NPV, sensitivity, specificity, and DOR for the visualization of breast cancer using 5-ALA-induced PpIX fluorescence plus PRODIGI. We also evaluated the technical feasibility, safety, and clinical workflow integration of this approach in the intraoperative setting. To the best of our knowledge, this is the first RCT to test a fully handheld, widefield fluorescence imaging device for real-time intraoperative breast cancer imaging of lumpectomy and mastectomy specimens and surgical cavities, as well as the first to report results for 15 and $30 \mathrm{mg} / \mathrm{kg} 5$-ALA-induced PpIX fluorescence in breast cancer patients.

Surgical margins are a significant challenge in the treatment of solid cancers [11]. During this study the Society of Surgical Oncology/American Society Radiation Oncology/American Society of Clinical Oncology released joint guidelines for BCS recommending a standard definition of a positive margin based on clinical evidence $[6,70]$. The guidelines define positive margins as "ink on tumor" for invasive breast cancer [6] and cancer within $2 \mathrm{~mm}$ of the inked margin for DCIS [70]. Surgeons disagree regarding the recommendations [19, 71, $72]$ and the effect of the guidelines on re-excision rates varies [71, 73-79]. Many studies still report suboptimal re-excision rates $[71,74,76,79-81]$, above the internationally accepted target of $10 \%[7,22]$, reinforcing the need for new imaging methods that allow surgeons and pathologists to visualize grossly occult disease on the lumpectomy and in the surgical cavity during index surgery.

5-ALA was well tolerated and enabled visualization of grossly obvious tumors and occult disease across all tumor grades (I-III) and types, including IDC and ILC with and without in situ disease. Both doses tested were lower than the only dose previously reported for clinical use in breast cancer $(40 \mathrm{mg} / \mathrm{kg})$ [48] and consistently induced bright red cancer fluorescence (contrasted against normal tissue AF) detected by the device.

PRODIGI was easy to use and practical due to its handheld form factor (e.g., non-cart based), which overcomes the large footprint limitation of existing closedand wide-field fluorescence surgical imaging systems. The device was safely integrated into the standard surgical workflow in both the operating room and the pathology suite without affecting standard specimen processing procedures. PpIX fluorescence imaging with PRODIGI was feasible in the presence of blue dye, which is commonly used in sentinel node mapping. Although there is a potential for the blue dye to absorb light in the red wavelength range, PpIX was visualized in tissues stained with blue dye. PRODIGI imaging within a small lumpectomy cavity was impeded by the form factor of the prototype which led to shadow artefacts due to the position of the LEDs. Additionally, although a standardized imaging distance of $\sim 10 \mathrm{~cm}$ was maintained when imaging excised tissue on the bench, achieving 
consistent distance for intracavity imaging was challenging. The next-generation device, currently being developed by our group, is anticipated to overcome these challenges by improving the optical power density output, re-configuring the optical components to maximize cavity and specimen surface illumination, including range finder technology to ensure a standardized working distance is maintained for optimal imaging and redesigning the form factor. For the free-hand imaging modality of the PRODIGI device, there is a potential for images taken to be blurry. We acknowledge that some of our images (Fig. 2A(b) and Fig. 2B(d)) are blurry and were not frames from a video. A blurry image, however, did not detract from real-time visualization of PpIX fluorescence. The next-generation device will include a tap-to-focus feature. A multicenter Phase III interventional imaging RCT will use this optimized device to evaluate the effectiveness of 5-ALA-induced PpIX fluorescence image-guided margin assessment and resection during BCS. Future studies may also evaluate fluorescence imaging during gross examination of specimens to facilitate rapid, targeted specimen sectioning and identification of areas for touch-prep cytology and frozensection analysis, to improve rapid decisions about additional tissue excision and location of positive margins in the surgical cavity.

Predictive values depend on disease prevalence, with a higher disease prevalence associated with higher PPV and lower NPV, and vice versa [82]. Analysis was, therefore, stratified by biopsy location as the prevalence of cancer cells is higher inside versus outside the tumor border. In our study, high PPV inside and high NPV outside the tumor border were observed for both 5-ALA doses, indicating that PRODIGI functioned as expected. However, sensitivity and specificity are generally accepted to not be influenced by differences in disease prevalence [83]. Thus, while these calculations are possible with biopsies from inside and outside the tumor border, more meaningful sensitivity and specificity are derived without stratification by biopsy location. When compared to MarginProbe, which uses non-imaging radiofrequency signals to alert surgeons about positive margins [84-86], our platform may be less likely to result in removal of cancer-negative tissues. Moreover, our approach is more sensitive and comparably specific to conventional BCS [86].

False positives and negatives were seen in both 5-ALA dose groups inside and outside the demarcated tumor border. False positives were only observed in 5-ALA patients (outside the tumor border), and not in controls, indicating likely ALA-induced PpIX production in nonmalignant cells. The majority of false positive biopsies (5/9), examined histologically, demonstrated nonmalignant proliferative changes (hyperplasia, columnar cell change, atypical ductal hyperplasia, sclerosing adenosis, and fibrocystic change) with infiltrating immune cells present in one biopsy. If we consider the detection of these "abnormal" proliferative changes as a desirable outcome of the test, the PPV to detect abnormal breast tissue (including malignant and non-malignant proliferative changes) increases to $89 \%$ and $70 \%$ for the low- and high-dose groups, respectively. Other studies using 5ALA have observed the accumulation of PpIX fluorescence in premalignant diseases [57], in areas with immune cell infiltration $[87,88]$ and in benign disease, such as Grade 1 meningiomas [89]. Removing nonmalignant tissues that are associated with increased breast cancer risk [90] may outweigh the potential effect on cosmesis during BSC, minimizing the clinical impact of false positives. Unlike other non-targeted approaches, such as circumferential cavity shaving [81], fluorescence imaging would conceivably allow for more spatially targeted revision of margins, reducing unnecessary removal of additional tissue which is desirable in optimizing cosmesis. Nevertheless, additional studies are needed to understand how 5-ALA behaves in benign and malignant breast tissues to improve their differentiation during intraoperative fluorescence imaging.

Eleven of the 14 false negative biopsies were collected from inside the tumor border, the majority of which (8/ 11) came from primary tumors that had observable red fluorescence elsewhere inside the demarcated tumor or in an area contiguous with the demarcated tumor on an adjacent slice, suggesting heterogeneity in biological factors that may influence 5-ALA uptake and the production, accumulation, and/or detection of PpIX in the primary tumor. For example, differences in tissue composition can affect optical properties and light transport in tissue which can affect the detection of PpIX. Moreover, endogenous fluorophores that emit high-intensity green AF (collagen, flavin adenine dinucleotide-FAD, reduced nicotinamide adenine dinucleotide-NADH) [91] may "mask" PpIX fluorescence, especially in small cancer foci.

Multifocal disease, associated with poorer disease-free survival [92], was also visualized in serially sectioned specimens. PpIX fluorescence revealed lobulated tumor borders and heterogenous tumor composition, which was consistent with patients' preoperative imaging/pathology but not appreciable by palpation. While some specimens had uniform bright red fluorescence tumors, others had heterogeneous (multifocal) bright red fluorescence foci with green connective tissue interspersed throughout the tumor, which is consistent with carcinoma-associated fibrosis [93]. We observed spatial heterogeneity in the density of fluorescent connective tissues in the surgical specimens during macroscopic examination with some specimens being homogeneously 
bright green and others showing a more mottled appearance. Moreover, increased microvasculature may preferentially absorb the $405 \mathrm{~nm}$ excitation light and emitted PpIX fluorescence. These findings may aid decisionmaking for oncoplastic surgical techniques [94] and identify patients with residual or multicentric disease beyond the primary tumor.

Limitations of the study include its single-center design, variability in the time to imaging, restriction on the total number of biopsies collected per patient, and a focus on visualization of carcinoma inside the serially sectioned specimen and not on the specimen margins. PMCC draws patients from various regional community practices representative of patients seen throughout Canada and the U.S. However, clinical practice by breast surgeons (A.M.E., W.L.L.) in our academic setting may vary from community practices [95]. Variability in the imaging time relative to administration of 5-ALA between patients is unavoidable in a surgical intervention study at a high-volume center. Nevertheless, we aimed to administer 5-ALA 2-4 $\mathrm{h}$ before anesthesia, to enable imaging between 2.5 and $5 \mathrm{~h}$ post-administration, which is clinically relevant for maximal PpIX signal [96]. The institution restricted the number and size of biopsies collected from inside and outside the demarcated tumor border. To maximize the number of PpIX red fluorescence areas analyzed histologically, biopsies were collected under fluorescence image guidance, possibly leading to a sampling selection bias. However, given the restrictions on biopsy collection, it would be difficult to collect enough biopsies without fluorescence image guidance to calculate sensitivity outside the tumor border. Lastly, future studies will assess the accuracy of 5-ALA-induced fluorescence visualization for the detection of positive margins during BCS.

\section{Conclusions}

Intraoperative fluorescence imaging is an emerging technique with significant potential to improve clinical outcomes in breast cancer patients. The superficial $(\sim 2 \mathrm{~mm}$ [56]) penetration of PRODIGI's $405 \mathrm{~nm}$ excitation light is more suitable for intraoperative margin assessment compared to NIR fluorescence imaging methods, which can image to depths of several centimeters [27, 28, 97, 98 ] and are, therefore, more likely to result in false positive margin readings. Unlike other non-image-based methods, including the FDA-approved MarginProbe [86], our approach produces a real-time color image of the anatomical location and extent of carcinoma with sub-millimeter resolution. The differing emission spectra of normal tissue AF and PpIX are visually distinguishable, providing excellent fluorescence contrast of the cancers against background healthy tissues and simplifying fluorescence image interpretation for the operator
[99]. This facilitates real-time decision-making by guiding surgeons to potential areas of microscopic disease within a macroscopic setting [99], and enabling treatment plan adjustments, which is not possible with current preoperative imaging modalities.

Our study also contributes to the growing clinical evidence of 5-ALA for intraoperative visualization of clinically occult cancer beyond neurosurgery where this approach is becoming the standard of care [43]. The versatile design of the novel handheld fluorescence imaging device could help to translate this approach to other cancer surgeries where margin assessment and imageguided resection are valuable. Future clinical adoption will be predicated on safe and effective device and contrast agent combinations that are easily integrated into the operating room workflow, meet the user's needs (wireless one-handed use), and are cost-sensitive.

\section{Abbreviations}

5-ALA HCl: 5-Aminolevulinic acid hydrochloride; AF: Autofluorescence; BCS: Breast-conserving surgery; CT: Computed tomography; DCIS: Ductal carcinoma in situ; DOR: Diagnostic odds ratio; FIGS: Fluorescence imageguided surgery; H\&E: Hematoxylin and eosin; IDC: Invasive ductal carcinoma; ILC: Invasive lobular carcinoma; LED: Light-emitting diode; LR: Local recurrence; MT: Masson's trichrome; NIR: Near infrared; NPV: Negative predictive value; ORO: Oil Red O; PA: Pathologist's assistant; PET: Positron emission tomography; PpIX: Protoporphyrin IX; PPV: Positive predictive value; qF: Quantitative fluorescence; RCT: Randomized controlled trial; WL: White light

\section{Supplementary Information}

The online version contains supplementary material available at https://doi. org/10.1186/s13058-021-01442-7

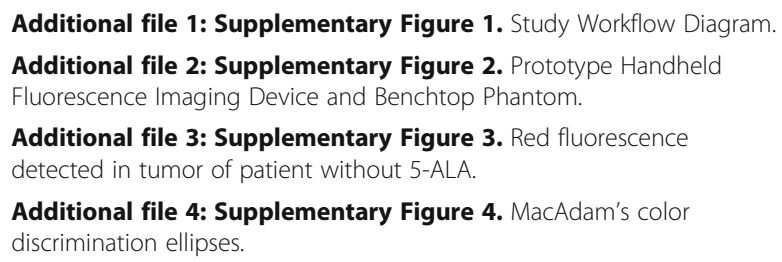

Additional file 4: Supplementary Figure 4. MacAdam's color discrimination ellipses.

Additional file 5: Supplementary Figure 5. Effect of tissue composition on PplX detection.

Additional file 6: Supplementary Figure 6. Draping and imaging with the PRODIGI device in the operating room.

Additional file 7: Supplementary Table 1. Statistical comparison of diagnostic accuracy measures for low and high dose 5-ALA.

\begin{abstract}
Acknowledgements
The authors thank the physicians, staff, and administration at Princess Margaret Cancer Center and Mount Sinai Hospital for their support. The authors acknowledge the generous provision of 5-ALA HCl for this RCT by photonamic GmbH and Co. KG (Pinneberg, Germany) and the helpful conversations with Dr. Ulrich Kosciessa, Dr. Andrea Ebling, Dr. Marcus Stocker, and Dr. Anne Moore. The provision of 5-ALA HCl for this study was governed by a Drug Transfer Agreement between photonamic and University Health Network (UHN). We also thank the members of the Advanced Optical Microscopy Facility at UHN for their assistance with microscopic imaging.
\end{abstract}

Authors' contributions

Study design and concept were conceived by RSD, WLL, AME, SJD, EC, and JW. Data acquisition was by KOP, AS, PJM, VS, MS, MF, LLT, DSD, EC, SM, AC, 
AP, and JW. Data analysis and interpretation was performed by KOP, SR, NTA PJM, EC, SJD, WLL, and AE. Statistical analysis was performed by KOP, TP, and ZL. Manuscript writing was performed by KOP and RSD and manuscript review was by SW, AS, IK, PJM, CG, SR, DSD WLL, AME, SJD, CFR, TP, and RSD. All authors have read and approved the final version of the manuscript.

\section{Funding}

Funding for this project was provided by the Canadian Institutes for Health Research (Grant \# 376995), Cancer Care Ontario (CCO), and the Princess Margaret Foundation (Turnball Family Foundation) to RSD.

\section{Availability of data and materials}

Data generated in this manuscript are available on request from the corresponding author (RSD) to comply with the Princess Margaret Cancer Center Institute ethics regulations to protect patient privacy. All requests will be promptly reviewed by the UHN Technology Development and Commercialization team to verify whether the request is subject to any intellectual property or confidentiality obligations. Any data and materials that can be shared will be released subject to a data transfer agreement.

\section{Declarations}

\section{Ethics approval and consent to participate}

This study was reviewed and approved by University Health Network's Research Ethics Board and Mount Sinai Hospital's Research Ethics Board. All participants consented to participate in this study prior to collection of any study data.

\section{Consent for publication}

All study participants consented to publication of deidentified study data in a publicly available print and internet publications.

\section{Competing interests}

RSD, KOP, CG, NTA, WL, AE, and SD are co-inventors on IP licensed to MolecuLight Inc. (Toronto, Canada) and photonamic GmbH \& Co. KG (Pinneberg, Germany) commercializing this technology. This study was a University Health Network (UHN) investigator-sponsored RCT (clinicaltrials.gov identifier NCT01837225) prior to IP licensing. RSD is the Founder, Chief Scientific Officer, Board member, and Shareholder of MolecuLight Inc. MolecuLight Inc. did not provide funding or other support, nor were any company staff involved directly or indirectly with this study. RSD conceived of the study and reviewed and edited the final manuscript. He did not recruit nor consent patients, nor collect, nor analyze data resulting from the study. 5-ALA HCl was provided by photonamic GmbH and Co. KG (Pinneberg, Germany) governed by a Drug Transfer Agreement between photonamic and UHN. RSD holds interest in photonamic GmbH \& Co. KG's subsidiary company (SBI ALApharma Canada Inc., Toronto, Canada) developing this technology for commercialization. KOP is employed by SBI ALApharma Canada Inc., but was solely employed by UHN during study data collection, data analysis and manuscript preparation. SBI ALApharma Canada Inc. was not involved directly or indirectly in this study. RSD is governed by a UHN Conflict of Interest Management Plan. All other authors declare that they have no competing interests.

\section{Author details}

'Princess Margaret Cancer Centre, University Health Network, Ontario Cancer Institute, 101 College Street, Toronto M5G 1L7, Ontario, Canada. 'Laboratory Medicine Program, University Health Network, 200 Elizabeth Street, 11th Floor Eaton Wing, Toronto M5G 2C4, Ontario, Canada. ${ }^{3}$ Biostatistics Department, University Health Network, 610 University Ave, Toronto M5T 2M9, Ontario, Canada. ${ }^{4}$ Dermatology Department, Toronto Western Hospital, University Health Network, 399 Bathurst St, Toronto M5T 2S8, Ontario, Canada. ${ }^{5}$ Department of Laboratory Medicine and Pathobiology, Faculty of Medicine, University of Toronto, 1 King's College Circle, Toronto M5S 1A8, Ontario, Canada. ${ }^{6}$ Surgical Oncology Department, Princess Margaret Cancer Centre of University Health Network, 610 University Ave, Toronto M5T 2M9, Ontario, Canada. 'Department of Medical Biophysics, Faculty of Medicine, University of Toronto, 101 College Street, Toronto M5G 1L7, Ontario, Canada. ${ }^{8}$ Techna Institute, University Health Network, 124-100 College Street, Toronto, Ontario M5G 1P5, Canada.
Received: 21 January 2021 Accepted: 25 May 2021

Published online: 12 July 2021

\section{References}

1. Chen K, Li S, Li Q, Zhu L, Liu Y, Song E, et al. Breast-conserving surgery rates in breast cancer patients with different molecular subtypes: an observational study based on Surveillance, Epidemiology, and End Results (SEER) database. Medicine (Baltimore). 2016;95:e2593.

2. Porter G, Wagar B, Bryant H, Hewitt M, Wai E, Dabbs K, et al. Rates of breast cancer surgery in Canada from 2007/08 to 2009/10: retrospective cohort study. CMAJ open. 2014;2(2):E102-8. https://doi.org/10.9778/cma jo.20130025.

3. Menes TS, Tartter PI, Bleiweiss I, Godbold JH, Estabrook A, Smith SR. The consequence of multiple re-excisions to obtain clear lumpectomy margins in breast cancer patients. Ann Surg Oncol. 2005;12(11):881-5. https://doi. org/10.1245/ASO.2005.03.021

4. Hennigs A, Fuchs V, Sinn HP, Riedel F, Rauch G, Smetanay K, et al. Do patients after reexcision due to involved or close margins have the same risk of local recurrence as those after one-step breast-conserving surgery? Ann Surg Oncol. 2016;23(6):1831-7. https://doi.org/10.1245/s10434-0155067-1.

5. Ali AN, Vapiwala N, Guo M, Hwang WT, Harris EE, Solin L. The impact of reexcision and residual disease on local recurrence after breast conservation treatment for patients with early stage breast cancer. Clin Breast Cancer. 2011;11(6):400-5. https://doi.org/10.1016/j.clbc.2011.08.003.

6. Moran MS, Schnitt SJ, Giuliano AE, Harris JR, Khan SA, Horton J, et al. Society of Surgical Oncology-American Society for Radiation Oncology consensus guideline on margins for breast-conserving surgery with whole-breast irradiation in stages I and II invasive breast cancer. Int J Radiat Oncol Biol Phys. 2014;88(3):553-64. https://doi.org/10.1016/j.jijrobp.2013.11.012.

7. Landercasper J, Attai D, Atisha D, Beitsch P, Bosserman L, Boughey J, et al. Toolbox to reduce lumpectomy reoperations and improve cosmetic outcome in breast cancer patients: The American Society of Breast Surgeons Consensus Conference. Ann Surg Oncol. 2015;22(10):3174-83. https://doi.org/10.1245/s10434-015-4759-x.

8. Vandergrift JL, Niland JC, Theriault RL, Edge SB, Wong YN, Loftus LS, et al. Time to adjuvant chemotherapy for breast cancer in National Comprehensive Cancer Network institutions. J Natl Cancer Inst. 2013;105(2): 104-12. https://doi.org/10.1093/jnci/djs506.

9. Pataky RE, Baliski CR. Reoperation costs in attempted breast-conserving surgery: a decision analysis. Curr Oncol. 2016;23(5):314-21. https://doi.org/1 0.3747/Co.23.2989

10. Baliski CR, Pataky RE. Influence of the SSO/ASTRO margin reexcision guidelines on costs associated with breast-conserving surgery. Ann Surg Oncol. 2017;24(3):632-7. https://doi.org/10.1245/s10434-016-5678-1.

11. Orosco RK, Tapia VJ, Califano JA, Clary B, Cohen EEW, Kane C, et al. Positive surgical margins in the 10 most common solid cancers. Sci Rep. 2018;8(1): 5686. https://doi.org/10.1038/s41598-018-23403-5.

12. Zhan QH, Fu JQ, Fu FM, Zhang J, Wang C. Survival and time to initiation of adjuvant chemotherapy among breast cancer patients: a systematic review and meta-analysis. Oncotarget. 2018;9(2):2739-51. https://doi.org/10.18632/ oncotarget.23086

13. Findlay-Shirras $\sqcup$, Outbih O, Muzyka CN, Galloway K, Hebbard PC, Nashed M. Predictors of residual disease after breast conservation surgery. Ann Surg Oncol. 2018;25(7):1936-42. https://doi.org/10.1245/s10434-018-6454-1.

14. Fisher S, Yasui Y, Dabbs K, Winget M. Re-excision and survival following breast conserving surgery in early stage breast cancer patients: a population-based study. BMC Health Serv Res. 2018;18(1):94. https://doi. org/10.1186/s12913-018-2882-7.

15. Hughes L, Hamm J, McGahan C, Baliski C. Surgeon volume, patient age, and tumor-related factors influence the need for re-excision after breastconserving surgery. Ann Surg Oncol. 2016;23(S5):656-64. https://doi.org/1 0.1245/s10434-016-5602-8.

16. Wilke LG, Czechura T, Wang C, Lapin B, Liederbach E, Winchester DP, et al. Repeat surgery after breast conservation for the treatment of stage 0 to II breast carcinoma: a report from the National Cancer Data Base, 2004-2010. JAMA Surg. 2014;149(12):1296-305. https://doi.org/10.1 001/jamasurg.2014.926.

17. Jeevan $\mathrm{R}$, Cromwell DA, Trivella M, Lawrence G, Kearins O, Pereira J, et al. Reoperation rates after breast conserving surgery for breast cancer among 
women in England: retrospective study of hospital episode statistics. BMJ. 2012;345(jul12 2):e4505. https://doi.org/10.1136/bmj.e4505.

18. Langhans L, Jensen MB, Talman MM, Vejborg I, Kroman N, Tvedskov TF. Reoperation rates in ductal carcinoma in situ vs invasive breast cancer after wire-guided breast-conserving surgery. JAMA Surg. 2017;152(4):378-84. https://doi.org/10.1001/jamasurg.2016.4751.

19. Lovrics PJ, Gordon M, Cornacchi SD, Farrokhyar F, Ramsaroop A, Hodgson N, et al. Practice patterns and perceptions of margin status for breast conserving surgery for breast carcinoma: National Survey of Canadian General Surgeons. Breast. 2012;21(6):730-4. https://doi.org/10.1016/j.breast.2 012.07.017.

20. Parvez E, Hodgson N, Cornacchi SD, Ramsaroop A, Gordon M, Farrokhyar F, et al. Survey of American and Canadian general surgeons' perceptions of margin status and practice patterns for breast conserving surgery. Breast $J$. 2014;20(5):481-8. https://doi.org/10.1111/tbj.12299.

21. Thill M, Baumann K, Barinoff J. Intraoperative assessment of margins in breast conservative surgery-still in use? J Surg Oncol. 2014;110(1):15-20. https://doi.org/10.1002/jso.23634.

22. Biganzoli L, Marotti L, Hart CD, Cataliotti L, Cutuli B, Kuhn T, et al. Quality indicators in breast cancer care: an update from the EUSOMA working group. Eur J Cancer. 2017;86:59-81. https://doi.org/10.1016/j. ejca.2017.08.017

23. Butler-Henderson $\mathrm{K}$, Lee $\mathrm{AH}$, Price Rl, Waring K. Intraoperative assessment of margins in breast conserving therapy: a systematic review. Breast. 2014; 23(2):112-9. https://doi.org/10.1016/j.breast.2014.01.002.

24. Singh $M$, Singh $G$, Hogan KT, Atkins KA, Schroen AT. The effect of intraoperative specimen inking on lumpectomy re-excision rates. World J Surg Oncol. 2010;8(1):4. https://doi.org/10.1186/1477-7819-8-4.

25. Maloney BW, McClatchy DM, Pogue BW, Paulsen KD, Wells WA, Barth RJ. Review of methods for intraoperative margin detection for breast conserving surgery. J Biomed Opt. 2018;23(10):1-19. https://doi.org/10.111 7/1.JBO.23.10.100901

26. Gray RJ, Pockaj BA, Garvey E, Blair S. Intraoperative margin management in breast-conserving surgery: a systematic review of the literature. Ann Surg Oncol. 2018;25(1):18-27. https://doi.org/10.1245/s10434-016-5756-4.

27. Whitley MJ, Cardona DM, Lazarides AL, Spasojevic I, Ferrer JM, Cahill J, et al. A mouse-human phase 1 co-clinical trial of a protease-activated fluorescent probe for imaging cancer. Sci Transl Med. 2016;8:320ra324.

28. Miampamba M, Liu J, Harootunian A, Gale AJ, Baird S, Chen SL, et al. Sensitive in vivo visualization of breast cancer using ratiometric proteaseactivatable fluorescent imaging agent, AVB-620. Theranostics. 2017;7(13): 3369-86. https://doi.org/10.7150/thno.20678.

29. Zhang RR, Schroeder AB, Grudzinski JJ, Rosenthal EL, Warram JM, Pinchuk $A N$, et al. Beyond the margins: real-time detection of cancer using targeted fluorophores. Nat Rev Clin Oncol. 2017;14(6):347-64. https://doi.org/10.1038/ nrclinonc.2016.212.

30. Nagaya T, Nakamura YA, Choyke PL, Kobayashi H. Fluorescence-guided surgery. Front Oncol. 2017;7:314. https://doi.org/10.3389/fonc.2017.00314.

31. DaCosta RS, Kulbatski I, Lindvere-Teene L, Starr D, Blackmore K, Silver JI, et al. Point-of-care autofluorescence imaging for real-time sampling and treatment guidance of bioburden in chronic wounds: first-in-human results. Plos one. 2015;10(3):e0116623. https://doi.org/10.1371/journal.pone.0116623.

32. Wu YC, Smith M, Chu A, Lindvere-Teene L, Starr D, Tapang K, et al. Handheld fluorescence imaging device detects subclinical wound infection in an asymptomatic patient with chronic diabetic foot ulcer: a case report. Int Wound J. 2015;13:449-53.

33. Wu YC, Kulbatski I, Medeiros PJ, Maeda A, Bu J, Xu L, et al. Autofluorescence imaging device for real-time detection and tracking of pathogenic bacteria in a mouse skin wound model: preclinical feasibility studies. J Biomed Opt. 2014;19(8):085002. https://doi.org/10.1117/1.JBO.19.8.085002.

34. Loh CS, MacRobert AJ, Bedwell J, Regula J, Krasner N, Bown SG. Oral versus intravenous administration of 5-aminolaevulinic acid for photodynamic therapy. Br J Cancer. 1993;68(1):41-51. https://doi.org/10.1038/bjc.1993.284

35. Ohgari Y, Nakayasu Y, Kitajima S, Sawamoto M, Mori H, Shimokawa O, et al. Mechanisms involved in delta-aminolevulinic acid (ALA)-induced photosensitivity of tumor cells: relation of ferrochelatase and uptake of ALA to the accumulation of protoporphyrin. Biochem Pharmacol. 2005;71(1-2): 42-9. https://doi.org/10.1016/j.bcp.2005.10.019.

36. Kobayashi H, Choyke PL. Target-cancer-cell-specific activatable fluorescence imaging probes: rational design and in vivo applications. Acc Chem Res. 2011;44(2):83-90. https://doi.org/10.1021/ar1000633.
37. Krieg RC, Messmann H, Rauch J, Seeger S, Knuechel R. Metabolic characterization of tumor cell-specific protoporphyrin IX accumulation after exposure to 5 -aminolevulinic acid in human colonic cells. Photochem Photobiol. 2002;76(5):518-25. https://doi.org/10.1562/0031-8655(2002)076< 0518:MCOTCS>2.0.CO;2.

38. Valdes PA, Leblond F, Kim A, Harris BT, Wilson BC, Fan X, et al. Quantitative fluorescence in intracranial tumor: implications for ALA-induced PpIX as an intraoperative biomarker. J Neurosurg. 2011;115(1):11-7. https://doi.org/1 0.3171/2011.2.JNS101451.

39. Valdes PA, Kim A, Brantsch M, Niu C, Moses ZB, Tosteson TD, et al. deltaaminolevulinic acid-induced protoporphyrin IX concentration correlates with histopathologic markers of malignancy in human gliomas: the need for quantitative fluorescence-guided resection to identify regions of increasing malignancy. Neuro Oncol. 2011;13:846-56.

40. Valdes PA, Bekelis K, Harris BT, Wilson BC, Leblond F, Kim A, et al. 5Aminolevulinic acid-induced protoporphyrin IX fluorescence in meningioma: qualitative and quantitative measurements in vivo. Neurosurgery. 2014;10(Suppl 1):74-82.

41. Millon SR, Ostrander JH, Yazdanfar S, Brown JQ, Bender JE, Rajeha A, et al. Preferential accumulation of 5-aminolevulinic acid-induced protoporphyrin IX in breast cancer: a comprehensive study on six breast cell lines with varying phenotypes. J Biomed Opt. 2010;15(1):018002. https://doi.org/10.111 7/1.3302811.

42. Palasuberniam $P$, Yang $X$, Kraus D, Jones $P$, Myers KA, Chen B. ABCG2 transporter inhibitor restores the sensitivity of triple negative breast cancer cells to aminolevulinic acid-mediated photodynamic therapy. Sci Rep. 2015; 18:13298.

43. Lakomkin N, Hadjipanayis CG. Fluorescence-guided surgery for high-grade gliomas. J Surg Oncol. 2018;118(2):356-61. https://doi.org/10.1002/jso.25154.

44. Nakai $Y$, Inoue K, Tsuzuki T, Shimamoto T, Shuin T, Nagao K, et al. Oral 5aminolevulinic acid-mediated photodynamic diagnosis using fluorescence cystoscopy for non-muscle-invasive bladder cancer: A multicenter phase III study. Int J Urol. 2018;25(8):723-9. https://doi.org/10.1111/iju.13718.

45. Inoue $K$, Anai $S$, Fujimoto $K$, Hirao $Y$, Furuse $H$, Kai F, et al. Oral 5aminolevulinic acid mediated photodynamic diagnosis using fluorescence cystoscopy for non-muscle-invasive bladder cancer: a randomized, doubleblind, multicentre phase II/III study. Photodiagnosis Photodyn Ther. 2015; 12(2):193-200. https://doi.org/10.1016/j.pdpdt.2015.03.008.

46. Tsuruki ES, Saito Y, Abe S, Takamaru H, Yamada M, Sakamoto T, et al. Evaluating the efficacy and safety of a novel endoscopic fluorescence imaging modality using oral 5-aminolevulinic acid for colorectal tumors. Endosc Int Open. 2016;4(1):E30-5. https://doi.org/10.1055/s-0041-110432.

47. Kitada M, Ohsaki Y, Yasuda S, Abe M, Takahashi N, Okazaki S, et al. Photodynamic diagnosis of visceral pleural invasion of lung cancer with a combination of 5aminolevulinic acid and autofluorescence observation systems. Photodiagnosis Photodyn Ther. 2017;20:10-5. https:/doi.org/10.1016/j.pdpdt.2017.08.013.

48. Ladner DP, Steiner RA, Allemann J, Haller U, Walt H. Photodynamic diagnosis of breast tumours after oral application of aminolevulinic acid. $\mathrm{Br}$ J Cancer. 2001;84(1):33-7. https://doi.org/10.1054/bjoc.2000.1532.

49. Matoba Y, Banno K, Kisu I, Aoki D. Clinical application of photodynamic diagnosis and photodynamic therapy for gynecologic malignant diseases: a review. Photodiagnosis Photodyn Ther. 2018;24:52-7. https://doi.org/10.101 6/j.pdpdt.2018.08.014.

50. Messmann H. 5-Aminolevulinic acid-induced protoporphyrin IX for the detection of gastrointestinal dysplasia. Gastrointest Endosc Clin N Am. 2000; 10(3):497-512. https://doi.org/10.1016/S1052-5157(18)30119-3.

51. Leunig A, Betz CS, Mehlmann M, Stepp H, Arbogast S, Grevers G, et al. Detection of squamous cell carcinoma of the oral cavity by imaging 5aminolevulinic acid-induced protoporphyrin IX fluorescence. Laryngoscope. 2000;110(1):78-83. https://doi.org/10.1097/00005537-200001000-00015.

52. Wang I, Clemente LP, Pratas RM, Cardoso E, Clemente MP, Montan S, et al. Fluorescence diagnostics and kinetic studies in the head and neck region utilizing low-dose delta-aminolevulinic acid sensitization. Cancer Lett. 1999; 135(1):11-9. https://doi.org/10.1016/s0304-3835(98)00271-7.

53. Vanseviciute R, Venius J, Zukovskaja O, Kanopiene D, Letautiene S, Rotomskis R. 5-aminolevulinic-acid-based fluorescence spectroscopy and conventional colposcopy for in vivo detection of cervical pre-malignancy. BMC Womens Health. 2015;15(1):35. https://doi.org/10.1186/s12905-015-0191-4.

54. Malik E, Berg C, Meyhofer-Malik A, Buchweitz O, Moubayed P, Diedrich K. Fluorescence diagnosis of endometriosis using 5-aminolevulinic acid. Surg Endosc. 2000;14(5):452-5. https://doi.org/10.1007/s004640000160. 
55. Kitada M, Ohsaki Y, Matsuda Y, Hayashi S, Ishibashi K. Photodynamic diagnosis of pleural malignant lesions with a combination of 5aminolevulinic acid and intrinsic fluorescence observation systems. BMC Cancer. 2015;15(1):174. https://doi.org/10.1186/s12885-015-1194-0.

56. Kanick SC, Davis SC, Zhao Y, Hasan T, Maytin EV, Pogue BW, et al. Dualchannel red/blue fluorescence dosimetry with broadband reflectance spectroscopic correction measures protoporphyrin IX production during photodynamic therapy of actinic keratosis. J Biomed Opt. 2014;19(7):75002 https://doi.org/10.1117/1.JBO.19.7.075002.

57. Ozog DM, Rkein AM, Fabi SG, Gold MH, Goldman MP, Lowe NJ, et al. Photodynamic therapy: a clinical consensus guide. Dermatol Surg. 2016; 42(7):804-27. https://doi.org/10.1097/DSS.0000000000000800.

58. A. Nabavi, H. Thurm, B. Zountsas, T. Pietsch, H. Lanfermann, U. Pichlmeier, M. Mehdorn, A. L. A. R. G. S. Group, Five-aminolevulinic acid for fluorescenceguided resection of recurrent malignant gliomas: a phase ii study. Neurosurgery. 2009;65:1070-1076. discussion 1076-1077

59. Stummer W, Pichlmeier U, Meinel T, Wiestler OD, Zanella F, Reulen HJ. Fluorescence-guided surgery with 5-aminolevulinic acid for resection of malignant glioma: a randomised controlled multicentre phase III trial. Lancet Oncol. 2006;7(5):392-401. https://doi.org/10.1016/S1470-204 5(06)70665-9.

60. Stummer W, Stepp H, Wiestler OD, Pichlmeier U. Randomized, prospective double-blinded study comparing 3 different doses of 5-aminolevulinic acid for fluorescence-guided resections of malignant gliomas. Neurosurgery. 2017;81(2):230-9. https://doi.org/10.1093/neuros/nyx074.

61. Stummer W, Tonn JC, Mehdorn HM, Nestler U, Franz K, Goetz C, et al. Counterbalancing risks and gains from extended resections in malignant glioma surgery: a supplemental analysis from the randomized 5aminolevulinic acid glioma resection study. Clinical article. J Neurosurg. 2011;114(3):613-23. https://doi.org/10.3171/2010.3.JNS097.

62. NX Development Corp. (2019). Gleolan (aminolevulinic acid hydrochloride): Highlights of prescribing information. Author.

63. Webber J, Kessel D, Fromm D. Plasma levels of protoporphyrin IX in humans after oral administration of 5-aminolevulinic acid. J Photochem Photobiol B. 1997;37(1-2):151-3. https://doi.org/10.1016/S1011-1344(96)0734 8-4.

64. Cozzens JW, Lokaitis BC, Moore BE, Amin DV, Espinosa JA, MacGregor M, et al. A Phase 1 dose-escalation study of oral 5-aminolevulinic acid in adult patients undergoing resection of a newly diagnosed or recurrent highgrade glioma. Neurosurgery. 2017;81(1):46-55. https://doi.org/10.1093/ neuros/nyw182.

65. Webber J, Kessel D, Fromm D. Side effects and photosensitization of human tissues after aminolevulinic acid. J Surg Res. 1997;68(1):31-7. https://doi. org/10.1006/jsre.1997.5004.

66. Olivotto I, Levine M. Clinical practice guidelines for the care and treatment of breast cancer: the management of ductal carcinoma in situ (summary of the 2001 update). CMAJ. 2001;165(7):912-3.

67. Hagiya AS, Etman A, Siddiqi IN, Cen S, Matcuk GR Jr, Brynes RK, et al. Digital image analysis agrees with visual estimates of adult bone marrow trephine biopsy cellularity. Int J Lab Hematol. 2018;40(2):209-14. https://doi.org/1 0.1111/ijlh.12768.

68. Monici M. Cell and tissue autofluorescence research and diagnostic applications. Biotechnol Annu Rev. 2005;11:227-56. https://doi.org/10.1016/ S1387-2656(05)11007-2.

69. Priye A, Ball CS, Meagher RJ. Colorimetric-luminance readout for quantitative analysis of fluorescence signals with a smartphone CMOS sensor. Anal Chem. 2018;90(21):12385-9. https://doi.org/10.1021/acs.ana Ichem.8b03521.

70. Morrow M, Van Zee KJ, Solin L, Houssami N, Chavez-MacGregor M, Harris $J R$, et al. Society of Surgical Oncology-American Society for Radiation Oncology-American Society of Clinical Oncology Consensus Guideline on margins for breast-conserving surgery with whole-breast irradiation in ductal carcinoma in situ. Ann Surg Oncol. 2016;23(12):3801-10. https://doi. org/10.1245/s10434-016-5449-z.

71. M. Morrow, P. Abrahamse, T. P. Hofer, K. C. Ward, A. S. Hamilton, A. W. Kurian, S. J. Katz, R. Jagsi, Trends in reoperation after initial lumpectomy for breast cancer: addressing overtreatment in surgical management. JAMA Oncol. 2017;3(10):1352-7. https://doi.org/10.1001/jamaoncol.2017.0774.

72. DeSnyder SM, Hunt KK, Smith BD, Moran MS, Klimberg S, Lucci A. Assessment of practice patterns following publication of the SSO-ASTRO consensus guideline on margins for breast-conserving therapy in stage I and II invasive breast cancer. Ann Surg Oncol. 2015;22(10):3250-6. https:// doi.org/10.1245/s10434-015-4666-1.

73. K. J. L. Blair, M., Re-excision rates following breast conserving therapy: a single institutions experience over ten years. Marshal J Med. 2017;3:68-74

74. Merrill AL, Coopey SB, Tang R, McEvoy MP, Specht MC, Hughes KS, et al. Implications of new lumpectomy margin guidelines for breast-conserving surgery: changes in reexcision rates and predicted rates of residual tumor. Ann Surg Oncol. 2016;23(3):729-34. https://doi.org/10.1245/s10434-015-491 6-2.

75. Chung A, Gangi A, Amersi F, Bose S, Zhang X, Giuliano A. Impact of Consensus Guidelines by the Society of Surgical Oncology and the American Society for Radiation Oncology on Margins for Breast-Conserving Surgery in Stages 1 and 2 Invasive Breast Cancer. Ann Surg Oncol. 2015; 22(Suppl 3):S422-7.

76. Rosenberger LH, Mamtani A, Fuzesi S, Stempel M, Eaton A, Morrow M, et al. Early adoption of the SSO-ASTRO Consensus Guidelines on margins for breast-conserving surgery with whole-breast irradiation in stage i and ii invasive breast cancer: initial experience from Memorial Sloan Kettering Cancer Center. Ann Surg Oncol. 2016;23(10):3239-46. https://doi.org/10.124 5/s10434-016-5397-7.

77. Schulman AM, Mirrielees JA, Leverson G, Landercasper J, Greenberg C, Wilke LG. Reexcision surgery for breast cancer: an analysis of the American Society of Breast Surgeons (ASBrS) MasterySM database following the SSO-ASTRO "No Ink on Tumor" Guidelines. Ann Surg Oncol. 2017;24(1):52-8. https://doi. org/10.1245/s10434-016-5516-5.

78. Heelan Gladden AA, Sams S, Gleisner A, Finlayson C, Kounalakis N, Hosokawa $\mathrm{P}$, et al. Re-excision rates after breast conserving surgery following the 2014 SSO-ASTRO guidelines. Am J Surg. 2017;214(6):1104-9. https://doi.org/10.1016/j.amjsurg.2017.08.023.

79. Tang SS, Kaptanis S, Haddow JB, Mondani G, Elsberger B, Tasoulis MK, et al. Current margin practice and effect on re-excision rates following the publication of the SSO-ASTRO consensus and ABS consensus guidelines: a national prospective study of 2858 women undergoing breast-conserving therapy in the UK and Ireland. Eur J Cancer. 2017;84:315-24.

80. Chagpar AB, Horowitz NR, Killelea BK, Tsangaris T, Longley P, Grizzle S, et al. Economic impact of routine cavity margins versus standard partial mastectomy in breast cancer patients: results of a randomized controlled trial. Ann Surg. 2017;265(1):39-44. https://doi.org/10.1097/SLA. 0000000000001799.

81. Chagpar AB, Killelea BK, Tsangaris TN, Butler M, Stavris K, Li F, et al. A randomized, controlled trial of cavity shave margins in breast cancer. $N$ Engl J Med. 2015;373(6):503-10. https://doi.org/10.1056/NEJMoa1504473.

82. Molinaro AM. Diagnostic tests: how to estimate the positive predictive value. Neurooncol Pract. 2015;2(4):162-6. https://doi.org/10.1093/nop/ npv030.

83. Lalkhen AG, McCluskey A. Clinical tests: sensitivity and specificity. BJA Educattion. 2008;8:221-3.

84. Coble J, Reid V. Achieving clear margins. Directed shaving using MarginProbe, as compared to a full cavity shave approach. Am J Surg. 2017; 213:627-30.

85. Pappo I, Spector R, Schindel A, Morgenstern S, Sandbank J, Leider LT, et al. Diagnostic performance of a novel device for real-time margin assessment in lumpectomy specimens. J Surg Res. 2010;160(2):277-81. https://doi.org/1 0.1016/j.jss.2009.02.025.

86. Schnabel F, Boolbol SK, Gittleman M, Karni T, Tafra L, Feldman S, et al. A randomized prospective study of lumpectomy margin assessment with use of MarginProbe in patients with nonpalpable breast malignancies. Ann Surg Oncol. 2014;21(5):1589-95. https://doi.org/10.1245/s10434-014-3602-0.

87. Omoto K, Matsuda R, Nakagawa I, Motoyama Y, Nakase H. False-positive inflammatory change mimicking glioblastoma multiforme under 5aminolevulinic acid-guided surgery: A case report. Surg Neurol Int. 2018;9:49.

88. Utsuki S, Oka H, Sato S, Shimizu S, Suzuki S, Tanizaki Y, et al. Histological examination of false positive tissue resection using 5-aminolevulinic acidinduced fluorescence guidance. Neurol Med Chir (Tokyo). 2007;47:210-3; discussion 213-214.

89. Wilbers E, Hargus G, Wolfer J, Stummer W. Usefulness of 5-ALA (Gliolan(R))derived PPX fluorescence for demonstrating the extent of infiltration in atypical meningiomas. Acta Neurochir (Wien). 2014;156(10):1853-4. https:// doi.org/10.1007/s00701-014-2148-z.

90. Nakhlis F. How do we approach benign proliferative lesions? Curr Oncol Rep. 2018;20(4):34. https://doi.org/10.1007/s11912-018-0682-1. 
91. DaCosta RS, Andersson H, Wilson BC. Molecular fluorescence excitationemission matrices relevant to tissue spectroscopy. Photochem Photobiol. 2003;78(4):384-92. https://doi.org/10.1562/0031-8655(2003)0780384: MFEMRT2.0.CO;2.

92. Vera-Badillo FE, Napoleone M, Ocana A, Templeton AJ, Seruga B, Al-Mubarak $M$, et al. Effect of multifocality and multicentricity on outcome in early stage breast cancer: a systematic review and meta-analysis. Breast Cancer Res Treat. 2014;146(2):235-44. https://doi.org/10.1007/s10549-014-3018-3.

93. Cox TR, Erler JT. Molecular pathways: connecting fibrosis and solid tumor metastasis. Clin Cancer Res. 2014;20(14):3637-43. https://doi.org/10.1158/1 078-0432.CCR-13-1059.

94. Macmillan RD, McCulley SJ. Oncoplastic breast surgery: what, when and for whom? Curr Breast Cancer Rep. 2016;8(2):112-7. https://doi.org/10.1007/s12 609-016-0212-9.

95. Dickson-Witmer D, Bleznak AD, Kennedy JS, Stewart AK, Palis BE, Bailey L, et al. Breast cancer care in the community: challenges, opportunities, and outcomes. Surg Oncol Clin N Am. 2011;20:555-580, ix.

96. Rick K, Sroka R, Stepp H, Kriegmair M, Huber RM, Jacob K, et al. Pharmacokinetics of 5-aminolevulinic acid-induced protoporphyrin IX in skin and blood. J Photochem Photobiol B. 1997;40(3):313-9. https://doi.org/10.1 016/S1011-1344(97)00076-6.

97. Korb ML, Hartman YE, Kovar J, Zinn KR, Bland Kl, Rosenthal EL. Use of monoclonal antibody-IRDye800CW bioconjugates in the resection of breast cancer. J Surg Res. 2014;188(1):119-28. https://doi.org/10.1016/j.jss.2013.11.1 089.

98. Lamberts LE, Koch M, de Jong JS, Adams A, Glatz J, Tranendonk MEG, Terwisscha van Scheltinga AGT, Jansen L, de Vries J, Lub-de Hooge MN, Schroder CP, Jorritsma-Smit A, Linssen MD, de Boer $E$, van der Vegt $B$, Nagengast WB, Elias SG, Oliveira S, Witkamp A, Mali WPTM, van der Wall E, Van Diest PJ, de Vries EG, Ntziachristos V, van Dam GM. Tumor-specific uptake of fluorescent bevacizumab-IRDye800CW microdosing in patients with primary breast cancer: a phase I feasibility study. Clin Cancer Res. 2016; 23(11):2730-41. https://doi.org/10.1158/1078-0432.CCR-16-0437.

99. Tummers WS, Warram JM, Tipirneni KE, Fengler J, Jacobs P, Shankar L, et al. Regulatory aspects of optical methods and exogenous targets for cancer detection. Cancer Res. 2017;77(9):2197-206. https://doi.org/10.1158/0008-54 72.CAN-16-3217.

\section{Publisher's Note}

Springer Nature remains neutral with regard to jurisdictional claims in published maps and institutional affiliations.

Ready to submit your research? Choose BMC and benefit from:

- fast, convenient online submission

- thorough peer review by experienced researchers in your field

- rapid publication on acceptance

- support for research data, including large and complex data types

- gold Open Access which fosters wider collaboration and increased citations

- maximum visibility for your research: over $100 \mathrm{M}$ website views per year

At $\mathrm{BMC}$, research is always in progress.

Learn more biomedcentral.com/submissions 